\title{
Structural architectures of polymer proton exchange membranes suitable for high-temperature fuel cell applications
}

\author{
Junming Dai ${ }^{1,3}, \mathrm{Yu}$ Zhang $^{1,3}$, Gang Wang $^{2^{*}}$ and Yongbing Zhuang ${ }^{1,3^{*}}$
}

\begin{abstract}
High-temperature proton exchange membrane (HT-PEM) fuel cells offer more advantages than low-temperature PEM fuel cells. The ideal characteristics of HT-PEMs are high conductivities, low-humidity operation conditions, adequate mechanical properties, and competitive costs. Various molecular moieties, such as benzimidazole, benzothiazole, imide, and ether ether ketone, have been introduced to polymer chain backbones to satisfy the application requirements for HT-PEMs. The most common sulfonated polymers based on the main chain backbones have been employed to improve the rties. Side group/chain engineering, including the introduction of $\mathrm{SO}_{3}{ }^{-}$on the side chain, grafting, branching, and crosslinking, has been widely applied to HTPEMs to further improve their proton conductivity, thermal stability, and mechanical properties. Currently, phosphoric acid-doped polybenzimidazole is the most successful polymer material for application in HT-PEMs. The compositing/ blending modification methods of polymers are effective in obtaining high PA-doping levels and superior mechanical properties. In this review, the current progress of various membrane materials used for HT-PEMs is summarized. The synthesis and performance characteristics of polymers containing specific moieties in the chain backbones applied to HT-PEMs are discussed systemically. Various modification approaches and their deficiencies associated with HT-PEMs are analyzed and clarified. Prospects and future challenges are also presented.
\end{abstract}

Keywords: proton exchange membranes, high-temperature fuel cells, structure-performance relationship, proton conductivity

\section{INTRODUCTION}

Fossil fuel is considered a nonrenewable energy source, but it is gradually running out. Its combustion is the largest contributor to accelerating atmospheric $\mathrm{CO}_{2}$ growth [1,2]. As such, novel and renewable energy-conversion systems should be developed for human society. Fuel cell technologies have emerged as promising candidates for electrochemical conversion devices because of their excellent characteristics, such as high fuel efficiencies, environmental friendliness, and steady supplies of energy [2-9]. As a clean energy source, hydrogen energy can transform into electricity in a nonpollution process via redox reactions in fuel cell systems. Fuel cells are categorized via some common classifications: alkaline fuel cells [10], phosphoric acid (PA) fuel cells, molten carbonic acid fuel cells, solid oxide fuel cells, and polyelectrolyte membrane fuel cells. According to the conduction of different ions $\left(\mathrm{OH}^{-}\right.$and $\left.\mathrm{H}^{+}\right)$, polyelectrolyte membrane fuel cells are classified as anion exchange membrane fuel cells $[11,12]$ and proton exchange membrane fuel cells (PEMFCs) $[13,14]$. PEMFCs are one of the most attractive technologies because of their clean, quiet, easy transportability, and high power density; as such, they are suitable for a wide range of potential applications in the automotive sector, energy power generation, and aerospace industry [15-18]. In 1959, Grubb [19] first proposed cation exchange membranes as solid polymer electrolytes in electrochemical cells for fuel cells. A dense PEM, which is a core constituent of PEMFCs, provides ionic pathways for proton migration from an anode to a cathode and acts as the gas barrier in a fuel system to prevent the mixing of reactants [20-24]. As shown in a single PEMFC system (Fig. 1a), $\mathrm{H}_{2}$ and $\mathrm{O}_{2}$ as chemical energies in the anode and cathode, respectively, can be converted into electrical energy via redox reactions in the designed fuel cells. Proton transfer generally requires two indispensable parts, namely, polymeric membrane materials and proton carriers, to work together. The performance of fuel cells can be affected by polymeric membrane structures, including chain backbones, side-chain groups, fillers, and supporting materials [19,25,26]. Currently, common proton carrier media for proton transportation include water, PA, and other ionic media (e.g., ionic liquids (ILs)). Proton carriers are indispensable in fuel cell systems. Low amounts of proton carriers weaken transportation. However, excessive proton carriers may damage the mechanical properties of membranes. Thus, favorable quantities of proton carriers in PEMs are necessary to obtain desirable membranes.

Polymers used in PEMs can be divided into two categories [18,23]: (1) neutral polymer membranes doped with ionic salts or inorganic acids and grafted acidophilic groups, such as Lewis acid-base complex membranes (e.g., PA-doped polybenzimidazoles [PBIs]) and (2) charged polymer membranes composed of acid-bearing functionalities (e.g., $\mathrm{SO}_{3}{ }^{-}$or $\mathrm{H}_{2} \mathrm{PO}_{4}{ }^{-}$) on the main chains or side chains of polymers. In 1967, Grot [27] first developed perfluorosulfonic acid membranes (Nafion, DuPont) for fuel cells; since then, great breakthroughs on proton-conducting ion exchange membranes have been achieved. Although Nafion membranes offer long operating lifetimes and satisfactory fuel cell performance below $80^{\circ} \mathrm{C}$, they show poor

\footnotetext{
${ }^{1}$ State Key Laboratory of Biochemical Engineering, Institute of Process Engineering, Chinese Academy of Sciences, Beijing 100190, China

${ }^{2}$ School of Chemistry and Chemical Engineering, Henan University of Technology, Zhengzhou 450001, China

${ }^{3}$ School of Chemical Engineering, University of Chinese Academy of Sciences, Beijing 100049, China

* Corresponding authors (emails: ybzhuang@ipe.ac.cn (Zhuang Y); gwang198@gmail.com (Wang G))
} 


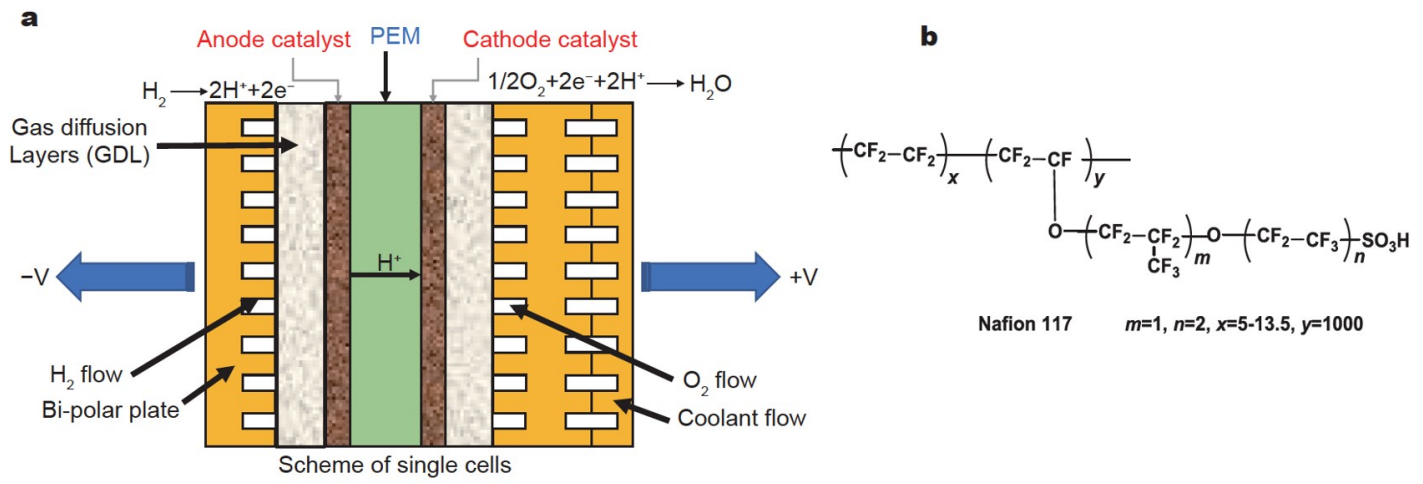

Figure 1 (a) MEA in single cells and (b) chain structure of Nafion 117.

ionic conductivities at high-temperature or low-humidity operating conditions. Consequently, the designs of new membrane materials with low costs and sufficient electrochemical characteristics have been extensively explored. Depending on working temperatures, PEMFCs can be classified into lowtemperature (typically below $80^{\circ} \mathrm{C}$ ) and high-temperature (100$200^{\circ} \mathrm{C}$ ) fuel cells [28-30]. One of the most well-known PEMs applied at low temperatures is a perfluorinated Nafion membrane, which was developed by DuPont [24,31]. The structure of a typical Nafion 117 membrane is shown in Fig. 1b [32-34]. Nafion membranes have many favorable properties, such as high conductivities under high hydration conditions and excellent chemical stability and durability. The unique properties of Nafion membranes originate from the presence of a polytetrafluoroethylene (PTFE) backbone and hydrophilic-hydrophobic phase separation structures within polymer membranes.

Although Nafion membranes have been widely investigated for PEMs, their applications have some significant defects $[35,36]$. For example, difficult synthesis processes and high material costs significantly limit their mass production and widespread commercialization [21,37]. Furthermore, the mechanical strengths of Nafion membranes are below $28 \mathrm{MPa}$, and they decrease at high operation temperatures because of a low glass transition temperature $\left(T_{\mathrm{g}}\right.$, from $\sim 55$ to $\sim 130^{\circ} \mathrm{C}$ ) $[38-$ 40]. The conductivity parameter of Nafion membranes strongly relies on hydration conditions and sufficient water molecules, ensuring proton transportation at temperatures less than $80^{\circ} \mathrm{C}$. However, water carriers are evaporated at temperatures above $100^{\circ} \mathrm{C}$, resulting in the failure of proton conductivity [41,42]. Another practical problem for Nafion membrane application is high fuel permeability leading to ionomer degradation [31]. Furthermore, the tolerance of low-temperature PEMFCs (LTPEMFCs) to fuel impurities (e.g., hydrogen in anodes) is low [21]. With these drawbacks, the applications of LT-PEMFCs are limited. Therefore, new membrane materials or modification approaches should be developed to prepare high-performance HT-PEMFCs for industrial applications.

HT-PEMFCs have been widely explored because of many promising characteristics $[43,44]$. In comparison with those of LT-PEMFCs, they significantly improve fuel cell performance and offer many advantages $[23,45]$, such as enhanced electrode kinetics and increased tolerance to fuel impurities (CO) $[43,46-$ 48]. Therefore, new polymer electrolyte membranes with high proton conductivities, low material cost, and other excellent properties for operating at high temperatures should be developed [49].
The membrane electrode assembly (MEA) includes porous gas diffusion layers (GDLs), catalyst layers, and polyelectrolyte membrane (Fig. 1a) [16,49,50]. MEA is an important building block for fuel cell tests and is typically fabricated by sandwiching a membrane between two pieces of gas diffusion electrodes (GDEs) with catalyst layers. Two ways were used to load catalysts for HT-PEMFCs. In most papers, catalysts are sprayed on GDLs to prepare GDEs, while few directly deposit them on membranes [51-53]. A binder is considered for MEA to disperse catalysts evenly in HT-PEMFCs. Binder inks work for catalyst dispersion and are fixed on the membrane or GDL, usually consisting of three parts: solvents, ionomers, and catalysts. For high-temperature acid-doped membranes, PBI is chosen as an ionomer because of its high chemical stability [45].

\section{Materials for high-temperature PEMs}

Various membrane materials have been applied to PEMs $[20,44,54]$. Thermally stable polymers with $-\mathrm{SO}_{3} \mathrm{H}$ groups in the main and side chains have been widely employed as PEMs because of their high proton conductivities and easy modification [20,55-57]. Sulfonated polymers are generally amphiphilic. With hydrophobic parts, PEMs possess excellent mechanical properties and thermal stability to prevent a polymer matrix from being dissolved in a proton carrier (e.g., hot water). Hydrophilic segments can retain and carry water to facilitate proton transport pathways [58].

Effective strategies have been reported to prepare novel membrane materials for HT-PEMs with high conductivities and excellent thermal and mechanical properties [38,57,59-63]: (1) main-chain backbone designs, (2) side group/chain engineering, (3) compositing, and (4) blending methods [64]. Benzimidazole (BI), benzothiazole (BT), and imide moieties in sulfonated polymer backbones can significantly improve thermal stability when they are applied to HT-PEMs. Side group/chain engineering approaches (e.g., grafting, branching, and crosslinking) have been developed to improve the performance of PEM. Currently, various acid-doping agents, including sulfuric acid, PA, and nitric acid, can provide a unique conductivity and outstanding thermal stability at increased temperatures $[65,66]$. PBI doped with PA is the most attractive and successful membrane material for application in HT -PEMFCs because of its high conductivity and thermal stability without any humidity condition requirements, leading to the significant simplification of a water management system [45,67-70]. For organic-inorganic composite membranes, various inorganic materials have been incorporated into a membrane matrix to obtain high 
conductivity and mechanical properties [71-76]. Furthermore, polymer blending is a flexible and economical approach to adjust performance by integrating excellent characteristics and alleviating the deficiencies of a single component [46,70]. ILs have been widely investigated to prepare HT-PEMs because of their excellent thermal stability and environmental friendliness [77-80].

\section{Proton conduction mechanism of PEMs}

Proton transfer in PEMs is influenced by many factors, including chain backbones, proton transfer channels, and inherent hydrophilicity. Based on different proton conduction circumstances, proton transfer in PEMs occurs through the vehicle and Grötthuss mechanisms (Fig. 2) [17,81]. In the vehicle mechanism, protons are transported via diffusion. For sulfonated polymers, the vehicle mechanism dominates proton transfer through $\mathrm{H}_{2} \mathrm{O}$ molecules, which act as vehicles to load $\mathrm{H}^{+}$ and consequently form $\mathrm{H}_{3} \mathrm{O}^{+}$. With the help of $\mathrm{SO}_{3}{ }^{-}$groupaggregated regions of hydrophilic segments in PEMs, the loaded $\mathrm{H}_{3} \mathrm{O}^{+}$can diffuse across membranes (Fig. 2a). In the Grötthuss mechanism, proton transfer through proton hopping between PAs via acid-base interactions, as indicated by the black arrow in
Fig. 2b. PA-doped polymer membranes conduct protons mainly following the Grötthuss-type hopping mechanism [45,82,83]. PA molecules act as proton carriers and conduct protons in the PBI membrane matrix by breaking and reforming hydrogen bonds. Increasing PA doping contents and temperature accelerates the proton transfer rate. Temperature and relative humidity $(\mathrm{RH})$ are also critical factors for the proton conductivities of polymers $[25,84]$. At high temperatures and low $\mathrm{RH}$, the Grötthuss mechanism mainly governs proton transport [17]. However, the vehicle mechanism works at low temperature and high $\mathrm{RH}$.

\section{MAIN CHAIN BACKBONE FABRICATION}

Many moieties, including BI, BT, imide, and ether ether ketone (EEK), have been introduced into the main-chain backbones to improve the thermal properties for operating at high temperature and low humidity [74,85-96]. The typical sulfonated polymers with various molecular moieties for PEM applications are shown in Fig. 3. Generally, two ways are adopted to construct sulfonated polymers: (1) post-sulfonation of polymers by immersing in concentrated sulfuric acid and (2) polycondensation from monomers bearing sulfonic acid groups [17]. It is an
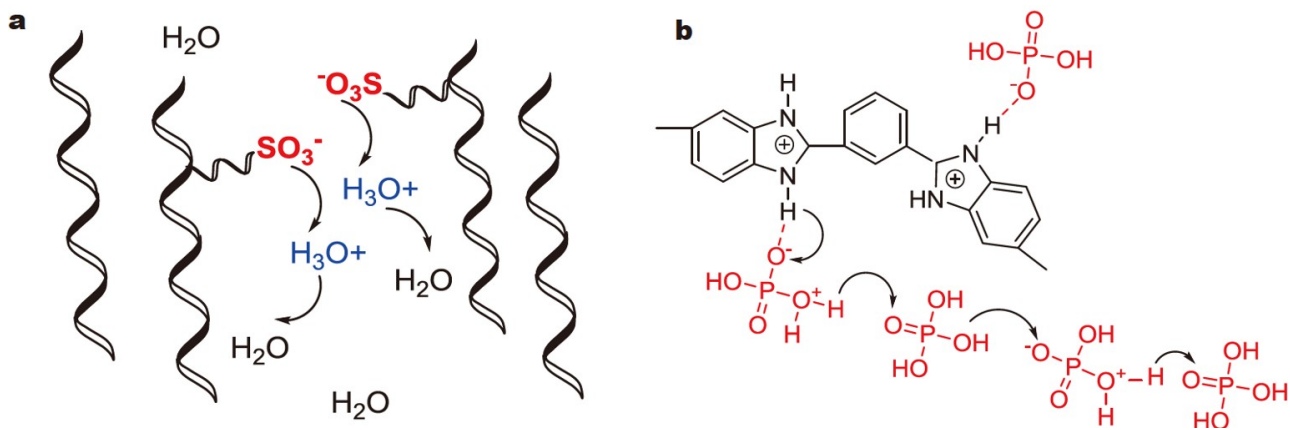

Figure 2 Proton transfer mechanism for (a) sulfonated polymers and (b) PA-doped PBI membranes.

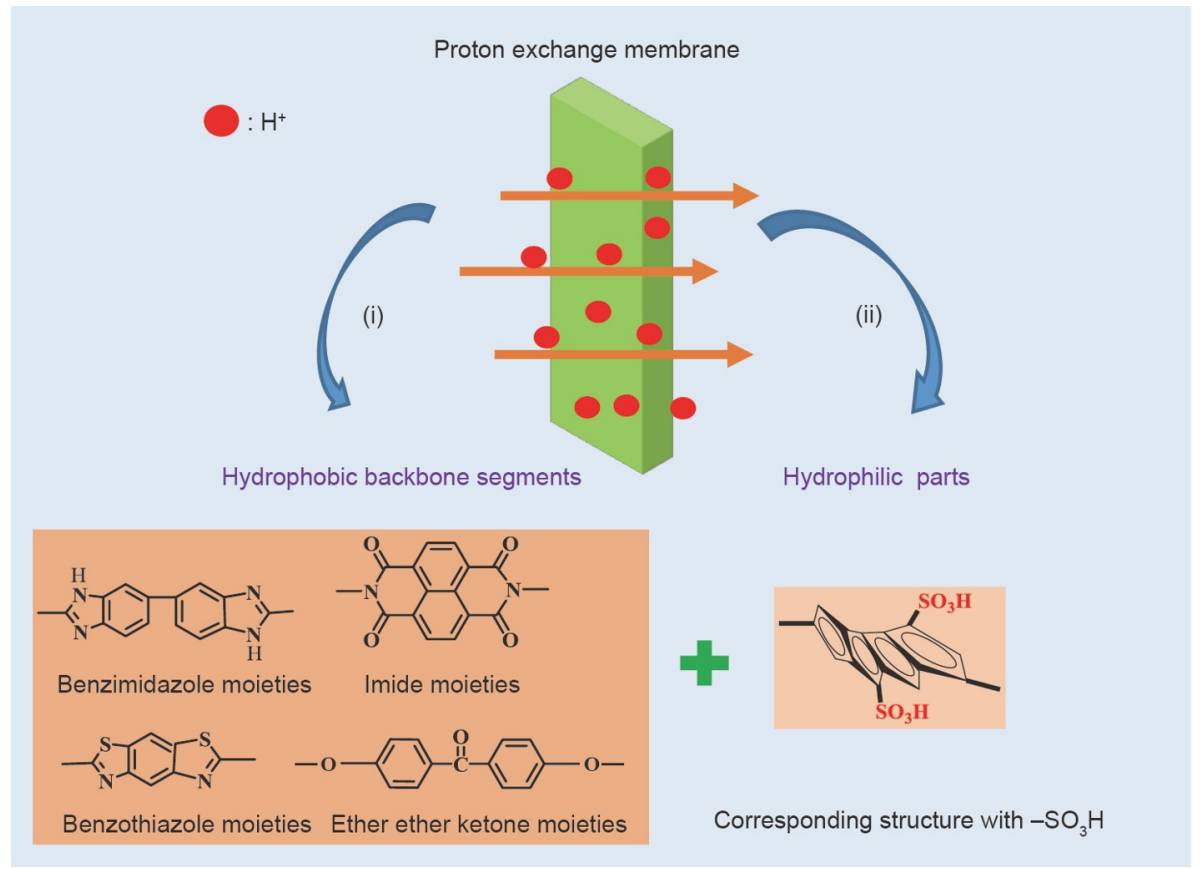

Figure 3 Typical main chain sulfonated polymers for PEM applications. 
inexpensive route by directing backbone sulfonation under mild reaction conditions. However, controlling the sulfonation degree of polymers is easier when using sulfonated monomers than when applying post-sulfonation in sulfuric acid [91-96].

\section{BI moieties}

PBIs are a kind of high-performance amorphous polymers containing $\mathrm{N}$-heterocycles with outstanding mechanical, thermal, and nonflammability properties at temperatures of up to $300^{\circ} \mathrm{C}$ [97-99]. The $T_{\mathrm{g}}$ of aromatic PBIs is about $425-436^{\circ} \mathrm{C}$, which is promising for HT-PEMs [29]. The cost of PBI materials used for synthesis is also a potential advantage compared with that of Nafion membranes. The typical structures and synthesis methods of PBIs are shown in Fig. 4.

Numerous PBI structures have been synthesized using tetraamines and diacid monomers via heterogeneous synthesis and homogeneous solution synthesis routes [98,100-102], as shown in Fig. 4a, b, respectively. The high-temperature heterogeneous synthesis of PBIs is usually a single-stage preparation process. Teraamines and diacid monomers can react at increased temperatures $\left(\sim 360^{\circ} \mathrm{C}\right)$ to generate water in the presence of catalysts such as triphenyl phosphite. The homogeneous solution method has been widely explored because of its moderate reaction temperatures, promising yields, and high molecular weights. Currently, most PBIs are synthesized through this homogeneous solution method by using polyphosphoric acid (PPA) or methanesulfonic acid (MSA) [102]. PA works as the condensation reagent and dehydrating agent at $190-220^{\circ} \mathrm{C}$. The purity of monomers should be high to prepare high-molecular-weight PBIs, and the concentration of total monomers in polycondensation should be controlled to a certain extent. Berber et al. [103] introduced a bipyridine structure (Bipy) into a PBIbackbone (Bipy-PBI) through the homogeneous solution method (Fig. 5a). Bipy-PBIs can be obtained with various molecular weights by controlling the polycondensation conditions, and the resulting membrane reaches the high peak power density of $779 \mathrm{~mW} \mathrm{~cm}^{-2}$.

Imidazole moieties conduct protons via intermolecular proton transfer. When they are introduced into polymer chain backbones, thermal, oxidative, and long-term stabilities may be enhanced [95,104]. However, pristine PBIs exhibit very low conductivity at low temperatures. The introduction of sulfonic groups into PBI chain backbones has been extensively investigated [105]. Peron et al. [106] prepared sulfonated poly[(1-(4,4diphenylether)-5-oxybenzimidazole)-benzimidazole] (sPBI-OO) via the post-sulfonation. After sulfonation, $T_{\mathrm{g}}$ of $\mathrm{PBI}-\mathrm{OO}$ is improved from 263 to $312^{\circ} \mathrm{C}$. Proton conductivity increases as temperature and humidity increase. Under the given conditions $\left(120^{\circ} \mathrm{C}\right.$ and $\left.100 \% \mathrm{RH}\right)$, the conductivity of the membrane is $0.05 \mathrm{~S} \mathrm{~cm}^{-1}$. Qing et al. [107] prepared a series of sulfonated PBI copolymers (sPBI-NF). They detected no significant weight loss below $350^{\circ} \mathrm{C}$. All sPBI-NF membranes have $T_{\mathrm{g}}>220^{\circ} \mathrm{C}$ [108].

The poor solubility of PBIs in conventional solvents leads to poor processability because of high rigidity and strong intermolecular acid-base interactions [45]. Many efforts have been devoted to improving solubility. Wang et al. [108] prepared soluble PBIs in organic solvents by using asymmetric dicarboxylic acid monomers (sPBI-N100, Fig. 5b), which disrupt their regular chain packing and thus improve solubility. Therefore, the resulting polymers can be easily fabricated into free-standing membranes by simple solution casting.

\section{BT moieties}

As a promising matrix material for PEMs, polybenzothiazole (PBT) is a high-performance heterocyclic polymer with excellent mechanical and thermal properties [109-111]. Sulfonated PBTs (sPBTs) are also suitable for high-temperature fuel cell applications because of their superior oxidative stability and super high proton conductivities [112,113]. They can be prepared through direct polycondensation from monomers containing sulfonated units [108,111]. Tan et al. [114] first synthesized sPBTs with high molecular weights and excellent solubility in organic solvents, such as $N$-methylpyrrolidone (NMP), dimethyl sulfoxide (DMSO), and $N, N$-dimethylformamide (DMF). sPBT membranes have high thermal stability below $350^{\circ} \mathrm{C}$. However, only a few sPBTs can be used as PEMs because most of the prepared sPBTs exhibit low molecular weights, poor solubility, and poor processability $[110,115]$.

sPBTs are commonly polymerized with 2,5-diamino-1,4benzenedithiol dihydrochloride (DABDT.2HCl) and various sulfonated dicarboxylic acid monomers in PPA solutions. Before polymerization, the bound hydrochloride in DABDT $2 \mathrm{HCl}$ must be removed by decompression and slight heating in nitrogen $[109,110]$.

PBTs exhibit no softening or glass transition before thermal degradation because of their high rigidity and strong intermolecular interactions. However, most PBTs are only soluble in strong protic acids, such as MSA and sulfuric acid, which prevent their processability to some extent $[95,110]$. The poor solubility of PBTs is attributed to high chain rigidity and strong intermolecular interactions. Many efforts have been devoted to improving their solubility in common organic solvents. Wang et

a

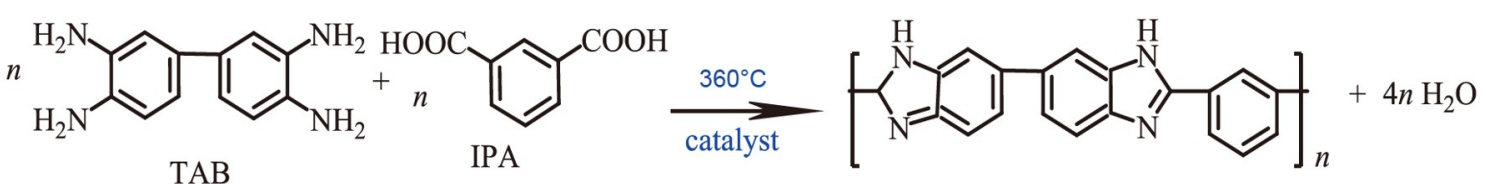

TAB

IPA

PBI

b

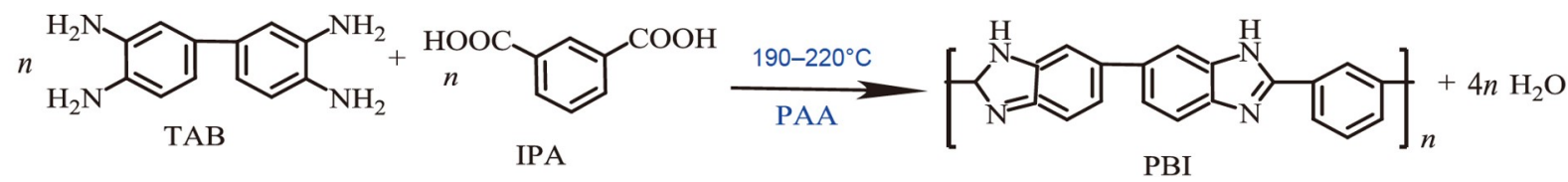

Figure 4 Synthesis of PBIs in two ways: (a) heterogeneous synthesis and (b) homogeneous solution synthesis. 


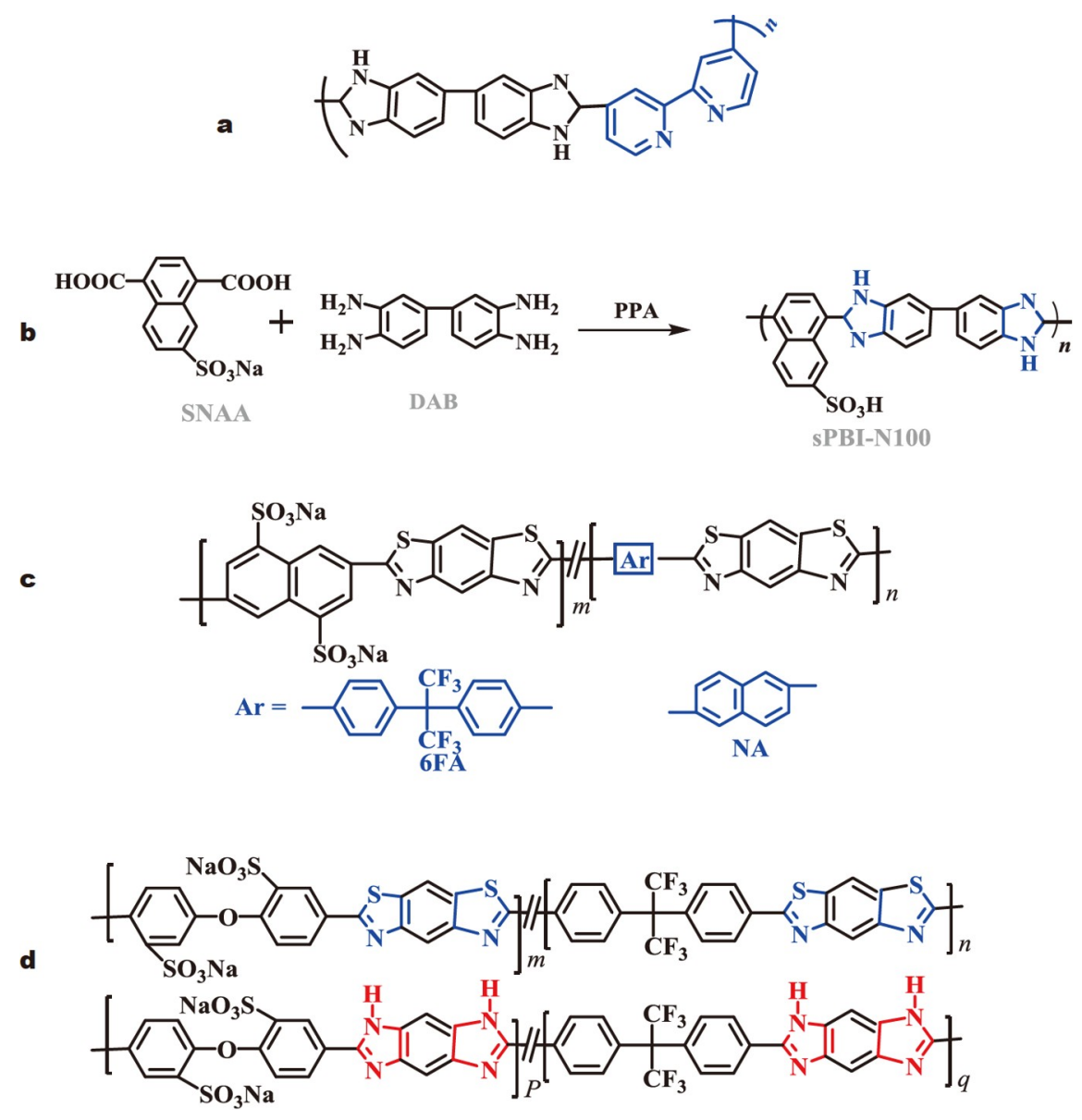

Figure 5 Various sPBI and sPBT copolymers: (a) structure of Bipy-PBI, (b) synthesis of sPBI-N100 based on asymmetric dicarboxylic acid monomers, (c) structure of sPBT-6FA or sPBT-NA, (d) structure of sPBT-BI.

al. [116] first integrated naphthalene units and flexible hexafluoroisopropylidene into the backbones of PBTs (sPBT-NA or sPBT-6FA, Fig. 5c), which reduce dimensional swelling and improve the mechanical properties of the membrane. The incorporation of flexible hexafluoroisopropylidene groups into polymer backbones enhances the solubility and processability of PBTs. Sulfonic acid groups initially lose weight at approximately $340^{\circ} \mathrm{C}$, while polymer backbones degrade at about $450^{\circ} \mathrm{C}$, indicating their excellent thermal stability. The proton conductivity of the sPBT membrane at $120^{\circ} \mathrm{C}$ and low $\mathrm{RH}$ also improves with the introduction of naphthalene units and flexible hexafluoroisopropylidene groups.

The incorporation of BI moieties into polymer chain backbones can improve PEM properties, including solubility, oxidative, and thermal stabilities [112,117,118]. Wang et al. [104] incorporated $\mathrm{BI}$ into polymer backbones to prepare random sPBTs (sPBT-BI, Fig. 5d). At room temperature, sPBT-BI polymers are soluble in many organic solvents, such as DMSO and NMP. $T_{\mathrm{g}}$ of sPBT-BI improves because of the introduction of BI structures. With the introduction of $20 \%$ BI moieties, $T_{\mathrm{g}}$ of sPBT-BI increases to $254^{\circ} \mathrm{C}$ compared with $235^{\circ} \mathrm{C}$ of the pristine PBT membrane. With the introduction of $\mathrm{BI}$, the tensile strength of sPBT-BI increases significantly to $125 \mathrm{MPa}$ compared with $79.9 \mathrm{MPa}$ of the pristine sPBTs membrane. Oxidative stability is characterized by immersing the membranes in Fenton's reagents for one hour. The residual weights of sPBT-BI membranes are above $96 \%$ and even reach $99 \%$ as the BI content increases, which is higher than $95 \%$ of the sPBT membrane; however, the proton conductivity of sPBT-BI decreases as the BI content increases because some sulfonic acids for proton transportation are consumed by BI via acid-base interactions. This phenomenon can be prevented by decreasing BI contents. The single cell performance and durability are also improved by the incorporation of $5 \%$ BI units in sPBTs. Therefore, the sPBT-BI70-5 membrane has a current density of $460 \mathrm{~mA} \mathrm{~cm}^{-2}$ at $100^{\circ} \mathrm{C}$ and $85 \% \mathrm{RH}$ and exhibits long-term durability for $500 \mathrm{~h}$.

\section{Imide moieties}

Polyimides are high-temperature engineering materials containing imide groups $[119,120]$. Polyimides with $\mathrm{SO}_{3}^{-}$are potential membrane materials for PEM applications [18]. In general, various polyimides can be synthesized from dianhydrides and diamines [121]. Currently, PEMs based on polyimides have shown promising research progress. Among them, sulfonated polyimides (sPIs) derived from 1,4,5,8-naphthalene tetracarboxylic dianhydride (NDTA) have been widely explored because of their high thermal stability, good mechanical properties, and outstanding film-forming capabilities [122-124].

Polyimides with $\mathrm{SO}_{3}^{-}$groups can transfer protons for PEM applications [125-128]. Yan et al. [126] prepared sPIs with the synthesized 4,4'-diaminodiphenylether-2,2-disulfonic acid (ODADS) and 4,4'-binaphthyl-1,1',8,8'-tetra-carboxylic dianhy- 
dride (BNTDA). The prepared copolyimide membranes achieve excellent mechanical properties and high proton conductivities, even after they are aged in water at $100^{\circ} \mathrm{C}$ for $800 \mathrm{~h}$. The initial degradation/decomposition temperatures of sulfonic acid groups and chain backbones are 280 and $500^{\circ} \mathrm{C}$, respectively. The sPI membranes tend to swell at a high sulfonation degree or at increased temperatures. Nevertheless, this problem can be effectively solved through copolymerization $[89,123,125]$.

Although RH can significantly affect the proton conductivities of PEMs, high conductivities should be obtained for sPIs incorporating hydrophilic segments. Bai et al. [88] introduced the hydrophilic soft segments of poly(ethylene oxide) (PEO) into sulfonated copolyimides. The current density of the membrane containing $5 \mathrm{~mol} \%$ PEO soft segments is higher than that of Nafion 112 at $120^{\circ} \mathrm{C}$ and $50 \%$ RH. However, the introduced PEO soft segments in the sulfonated PIs reduce the thermal stability.

\section{EEK moieties}

Poly(ether ether ketone) (PEEK) has been widely reported for PEMs because of their low cost, high thermal stability, and excellent mechanical properties. Sulfonated PEEK (sPEEK) can be synthesized via aromatic nucleophilic substitution reactions [129]. Xing et al. [130] adopted sulfuric acid (95-98 wt\%) as the sulfonating agent to prepare a series of sPEEKs. The sulfonation degree of sPEEKs can be adjusted in terms of reaction time and immersion temperature.

sPEEK membranes exhibit excellent thermal stability with sulfonic acid groups decomposed at $240^{\circ} \mathrm{C}$ [129]. Their proton conductivities can reach up to $0.11 \mathrm{~S} \mathrm{~cm}^{-1}$ at $150^{\circ} \mathrm{C}$ and $100 \%$ $\mathrm{RH}$. Sulfonated aromatic hydrocarbon polymers present excessive swelling and low dimensional stability. The introduction of BI moieties into sulfonic polymers is a potential approach to improve their dimensional, oxidative, and thermal stabilities [131]. The proton transportation and acid-base interactions in sulfonated polyaryletherketone bearing BI are shown in Fig. 6. Sulfonic acid groups are consumed by BI units via acid-base interactions, resulting in decreased swelling ratios.

\section{SIDE-GROUP/CHAIN ENGINEERING}

The proton conductivities and tensile strengths of various sulfonated polymers are summarized in Table 1. The introduction of hydrophilic group $\left(\mathrm{SO}_{3}{ }^{-}\right)$promoted high proton conductivity and sufficient tensile strengths, but high sulfonation degrees of polymers lead to serious swelling in water and even to dissolving in hydrophilic solvents [132-139]. The sulfonation degrees of sulfonated polymers should be controlled with high proton conductivity and superior dimensional stability. Hence, structural modifications, including $\mathrm{SO}_{3}{ }^{-}$introduction to the side chain, grafting, branching, and crosslinking, have been used to develop desirable membrane materials with acceptable swelling and high proton conductivity.

\section{Introduction of $\mathrm{SO}_{3}{ }^{-}$to the side chain}

Sulfonic acid groups can be bonded to polymer backbones or can work as side-chain pendant groups for developing proton transfer; thus, sulfonated polymers can be classified as the main

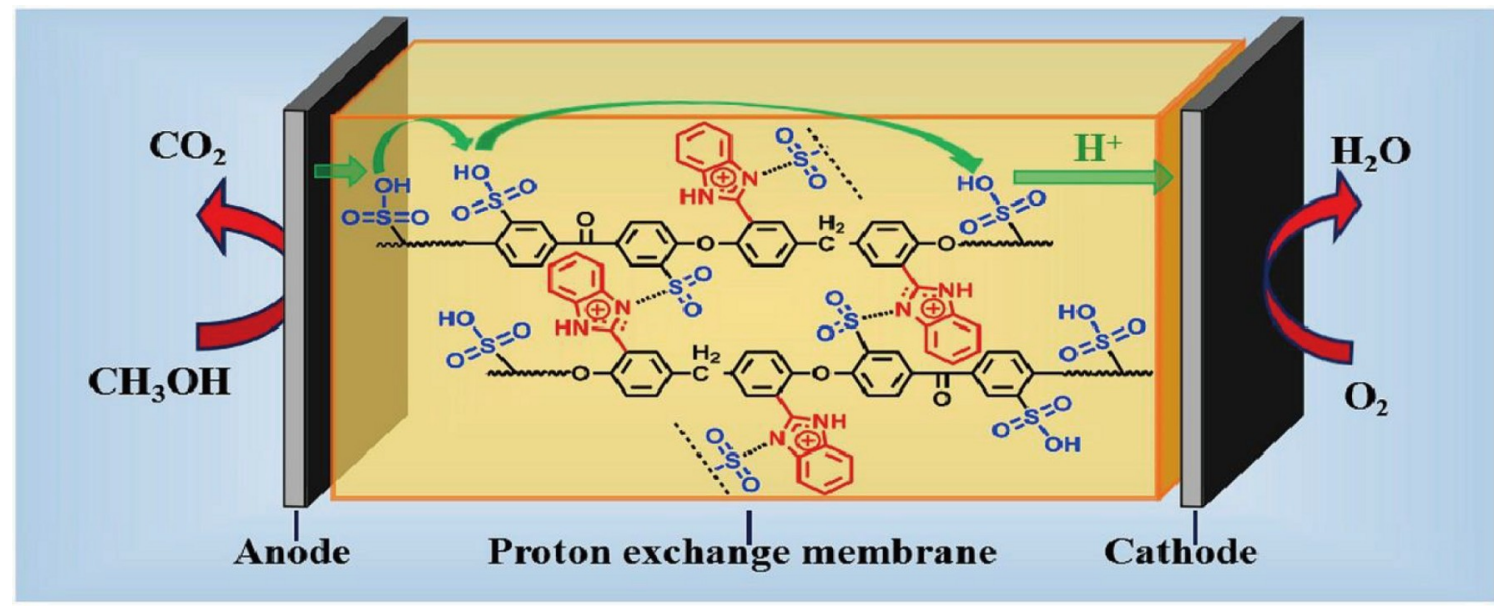

Figure 6 Proton conduction of sulfonated polyaryletherketone bearing BI moieties. Reprinted with permission from Ref. [131]. Copyright 2019, Elsevier.

Table 1 Tensile strengths, conductivities, and peak power densities of sulfonated polymer membranes

\begin{tabular}{|c|c|c|c|c|c|c|}
\hline Type of membrane & $\begin{array}{c}\text { Operational } \\
\text { temperature }\left({ }^{\circ} \mathrm{C}\right)\end{array}$ & $\mathrm{RH}(\%)$ & $\begin{array}{l}\text { Tensile strength } \\
(\mathrm{MPa})\end{array}$ & $\begin{array}{l}\text { Proton conductivity } \\
\left(\mathrm{S} \mathrm{cm}^{-1}\right)\end{array}$ & $\begin{array}{l}\text { Peak power density } \\
\left(\mathrm{mW} \mathrm{cm}^{-2}\right)\end{array}$ & Ref. \\
\hline sPI-main chain & 120 & 100 & - & Better than Nafion 115 & - & [88] \\
\hline sPI-main chain & 140 & 100 & - & 0.1 & - & [89] \\
\hline sPBI-main chain & 120 & 100 & 38 & 0.05 & - & [106] \\
\hline sPEEK-main chain & 150 & 100 & - & 0.11 & - & [129] \\
\hline sPI-side chain & 120 & 100 & - & 1 & - & [135] \\
\hline sPI-side chain & 130 & 100 & 129 & $0.2-0.3$ & - & [136] \\
\hline sPAEK-main chain & 120 & 100 & 45.34 & 0.152 & 607 & [137] \\
\hline sPT-main chain & 120 & 100 & 47.53 & 0.166 & - & [139] \\
\hline
\end{tabular}


and side chain types [5,136]. In general, the water uptake, conductivity, and water stability of side-chain-type sulfonated polymers are higher than those of main-chain-type sulfonated polymers [140,141]. Hu et al. [136] synthesized a series of polyimides with sulfophenyl pendant groups. Weight is initially lost at $320^{\circ} \mathrm{C}$ because of the decomposition of sulfonic acid groups. The side-chain-type sPIs exhibit high proton conductivities of $0.2-0.3 \mathrm{~S} \mathrm{~cm}^{-1}$ at $130^{\circ} \mathrm{C}$, but their peak power density is lower than that of Nafion 115. The introduction of nonsulfonated diamines enhances the mechanical properties of membranes. To decrease the mechanical loss of side-chain-type sulfonated homopolyimides (homo-sPIs) [142], researchers prepared a series of sulfonated copolyimides (co-sPIs) by using nonsulfonated diamines [143]. Changes in the dimensions of cosPIs membranes are lower than those of the homo-sPIs. Li et al.
[144] obtained sulfonated copolyimides with $-\mathrm{SO}_{3} \mathrm{H}$ on side chains (Fig. 7a). Sulfonic acid groups lose weight at around $300^{\circ} \mathrm{C}$, and $T_{\mathrm{g}}$ is detected below $500^{\circ} \mathrm{C}$, indicating their potential applications for HT-PEMs. Cheng et al. [137] prepared a sulfonated poly(arylene ether ketone) (sPAEK) copolymer with sulfoalkyl pendant groups via the nucleophilic polycondensation (Fig. 7c). The resulting membrane exhibits a proton conductivity of $0.152 \mathrm{~S} \mathrm{~cm}^{-1}$ and a peak power density of $607 \mathrm{~mW} \mathrm{~cm}^{-2}$ at $120^{\circ} \mathrm{C}$ and $100 \% \mathrm{RH}$, which are higher than the corresponding ones of Nafion 117 under the same conditions. The methanol permeabilities of the sPAEK membrane are lower and its relative selectivities are higher than those of Nafion 117. However, tensile strength decreases as the contents of pendant sulfoalkyl groups increase. Shao et al. [145] prepared side-chain-type sulfonated naphthalene-base poly(arylene ether ether ketone)<smiles>CC(C)(C)N1C(=O)c2ccc3c4c(ccc(c24)C1=O)C(=O)N(c1ccc(C(=O)c2cccc(S(=O)(=O)O)c2)c(C(=O)c2cccc(S(=O)(=O)O)c2)c1)C3=O</smiles><smiles>CCOc1cc(-c2ccc(N3C(=O)c4ccc5c6c(ccc(c46)C3=O)N(CCOC)C5=O)c(OC)c2)ccc1CC</smiles><smiles>CCOc1ccc(S(=O)(=O)O)cc1</smiles>

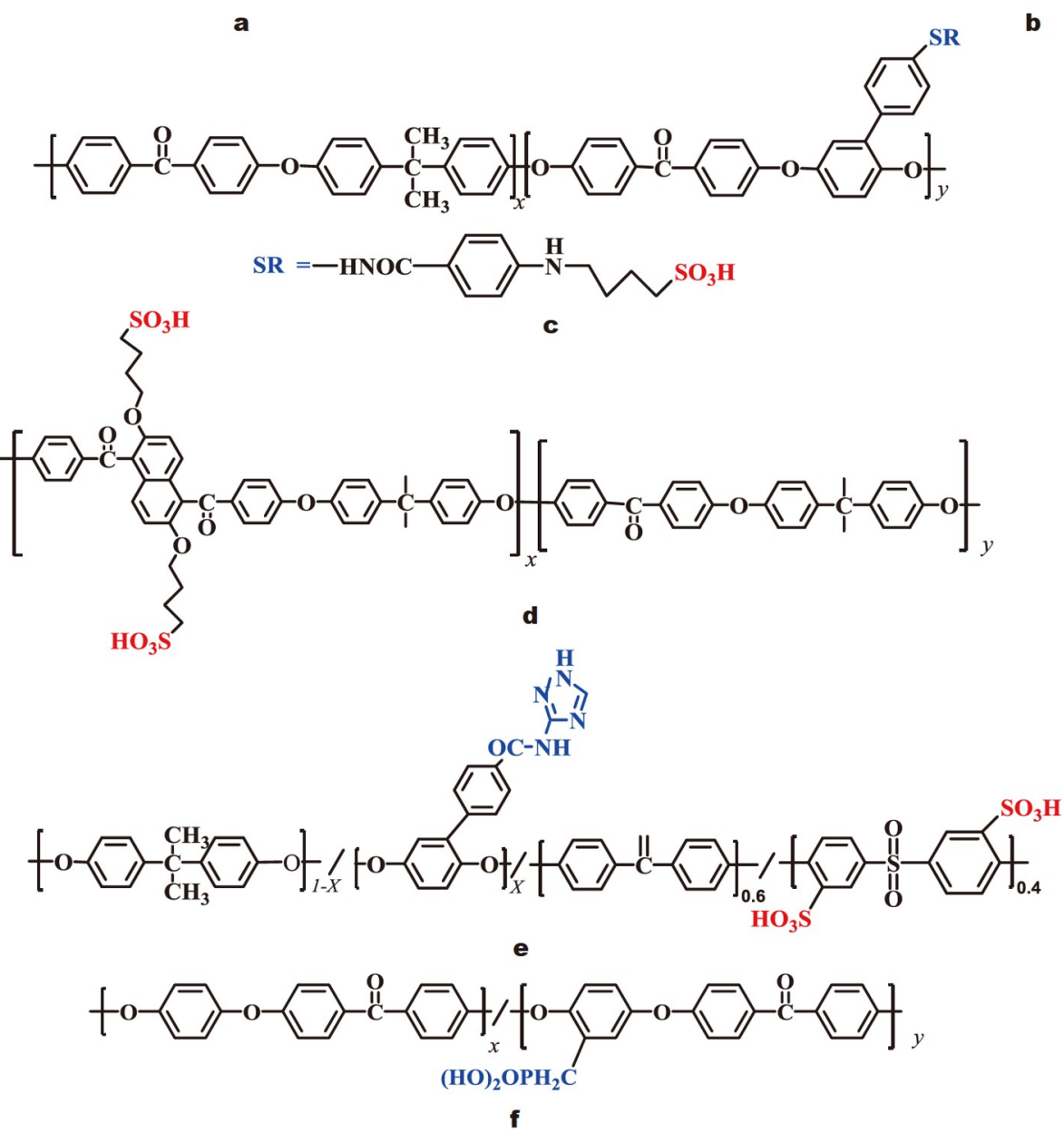

Figure 7 Polymers bearing side-chain groups: (a) copolyimides based on 2,2'-bis(3-sulfobenzoyl)benzidine (2,2'-BSBB); (b) polyimide electrolyte with longer sulfophenoxypropoxy pendant groups; (c) sPAEK copolymers with a pendant sulfoalkyl group; (d) sulfonated naphthalene-based sPAEK copolymers containing methoxy groups; (e) triazole-grafted sPTs; and (f) functionalized phosphonated PEEKs. 
copolymers (sPAEKs, Fig. $7 \mathrm{~d}$ ). $T_{\mathrm{g}}$ of sPAEKs increases as naphthalene contents increase. The highest $T_{\mathrm{g}}$ of the sPAEK-80 membrane is $301^{\circ} \mathrm{C}$.

The length of the side chain in sulfonated polymers strongly affects the performance of fuel cells. A polyimide electrolyte with long sulfophenoxypropoxy pendant groups exhibits a high proton conductivity of $1 \mathrm{~S} \mathrm{~cm}^{-1}$ at $120^{\circ} \mathrm{C}$ and $100 \% \mathrm{RH}$ (Fig. $7 \mathrm{~b}$ ) [135]. However, the proton conductivity of membranes does not improve as the length of the side chain further increases.

\section{Grafting}

Amphoteric $N$-heterocycles, including pyrazole, imidazole, oxadiazole, and triazole, can act as proton donors and proton acceptors; as such, membranes have high proton conductivity and thermal stability at high temperatures [14,146,147]. Li et al. [139] grafted triazole groups on the side chains of sulfonated poly(arylene ether ketone sulfone)s (sPTs, Fig. 7e). All sPTs show good thermal stability for PEM applications. The thermal stability of sPAEK increases as the triazole group contents increase because of interactions between triazole and sulfonic acid groups. The grafted sPTs have a proton conductivity of $0.166 \mathrm{~S} \mathrm{~cm}^{-1}$ at $120^{\circ} \mathrm{C}$, which is higher than that of nongrafted sPTs.

In previous studies, the development of PEMs with phosphonic acid groups as protogenic moieties has attracted considerable attention for improving thermal and chemical stabilities and reducing water swelling $[138,148,149]$. Phosphonated copolyimides have high water uptake and stable proton conductivity at high temperatures and low RH [150]. Bano et al. [92] synthesized the functionalized phosphonated PEEKs with triethyl phosphite through two steps, namely, PEEK chloromethylation and phosphonation via a classical Arbuzov reaction (Fig. 7f). The resulting membranes exhibit good chemical and thermal stabilities and high proton conductivity $\left(0.047 \mathrm{~S} \mathrm{~cm}^{-1}\right)$ at $120^{\circ} \mathrm{C}$ and $30 \% \mathrm{RH}$.

\section{Branching}

Branched structures can be added to polymers to improve the oxidative stability, dimensional stability, and proton conductivity of PEMs effectively $[110,151,152]$. The chemical stabilities and mechanical properties of the branched sPIs containing fluorine units (Fig. 8a) are superior to those of linear sPIs [152]. Han et al. [40] prepared two highly branched sulfonated poly(arylene ether)s containing carbazole structures (Fig. 8b). Sulfonic acid groups degrade at $210^{\circ} \mathrm{C}$, indicating an excellent thermal resistance. The tensile strength of the sulfonated branched SBP-Cz-10 membrane is $41 \mathrm{MPa}$, which is higher than $28 \mathrm{MPa}$ of the Nafion 117 membrane.

Branched structures in polymers help reduce methanol permeability while maintaining sufficient proton conductivity for the membranes. The branched Br-30-sPAEK-30 membrane (Fig. 8c) exhibits a low methanol permeability of $1.25 \times$ $10^{-7} \mathrm{~cm}^{2} \mathrm{~s}^{-1}$, which is lower than $1.78 \times 10^{-7} \mathrm{~cm}^{2} \mathrm{~s}^{-1}$ of the linear sPAEK membrane and $1.55 \times 10^{-6} \mathrm{~cm}^{2} \mathrm{~s}^{-1}$ of the Nafion 117 membrane [153]. The branched structures increase the free volume in membranes and thus provide more space for hydration, which facilitates high water uptake and desired proton conductivity. However, high water uptake and swelling ratios of the branched membranes reduce their mechanical strengths.

A superior proton conductivity can be achieved by preparing a novel sulfonated star-hyperbranched core-shell polyimide (sHB-
PI) by introducing a trifunctional monomer, tris(4-aminophenyl)amine (TPAP) [154] (Fig. 8d). The desulfonation temperature of sHB-PI is about $280^{\circ} \mathrm{C}$. However, the oxidation stability of the sHB-PI membrane is low because the shell of NTDA-BDSA is easily attacked by radicals in Fenton's reagent.

\section{Crosslinking}

Crosslinking is a powerful approach and is widely used to prevent methanol permeability and alleviate excessive swelling for sulfonated polymers in a hydrophilic solvent. With the formed network structures, the membrane achieves excellent physicochemical stability at high temperatures $[53,58,155,156]$. Han et al. [155] reported end-group-crosslinked sulfonated poly(arylene-ether sulfone) (sPAES) membranes with vinyl polysulfone (VPSf) as the crosslinker. sPAES membranes were modified by crosslinking with VPSf through the thiol-group introduction (Fig. 9a). As expected, the chemical stability of crosslinked membranes improves, and their mechanical performance is better than that of the corresponding linear sPAES membranes. However, such modification methods restrict the segment movement, leading to a decrease in proton conductivity. Li et al. [157] synthesized sPT with amino groups on side chains (abbreviated as AMSP). The crosslinked networks are formed by triazole-grafted 3-glycidyloxypropyltrimethoxysilane (GT), as shown in Fig. 9b. The desulfonation temperature of the crosslinked AMSP/GT membranes enhances compared with that of noncrosslinked membranes because of the improved interactions between GT and AMSP. The tensile strengths of the crosslinked AMSP/GT-30 membrane increase to $63.11 \mathrm{MPa}$ compared with $46.25 \mathrm{MPa}$ of noncrosslinked membranes. The proton conductivity of AMSP/GT is $0.135 \mathrm{~S} \mathrm{~cm}^{-1}$ at $100^{\circ} \mathrm{C}$. Zhang et al. [158] prepared a crosslinked sPIs membrane by introducing imidazole groups, which react with 3-glycidoxypropyltrimethoxysilane (KH-560) in an acid solution (Fig. 9c). Thus, the resulting crosslinking membrane exhibits high proton conductivity.

\section{COMPOSITING/BLENDING}

Composting and blending membranes based on PBIs and other basic polymers are successful membrane materials for application in HT -PEMFCs. Among them, PBIs doped with PA is the most attractive membrane material because of its thermal stability and high conductivity without any humidity condition requirements. The proton conductivity and mechanical strength of some reported polymers [3,30,46,51-53,65,66,71,82,86,103, 159-172] are summarized in Table 2. Composting and blending membranes still have some challenges for their applications in HT-PEMFCs. For example, when the amount of acid medium is too low, proton conductivity is inadequate; by contrast, excessive PA dopants significantly impair the mechanical strength of PEMs because of the plasticizing effect of PA, especially at increased temperatures. Acid-base membranes frequently undergo acid leaching, resulting in catalyst poisoning under harsh operating conditions.

\section{PA-doped composite membranes}

The intrinsic conductivity of PBI-based membranes can be negligible because of low water uptake $[173,174]$. The proton conductivity of sulfonated PBIs mainly relies on $\mathrm{SO}_{3}{ }^{-}$to form hydrogen-bond networks for efficient proton transport under hydrated conditions. However, sulfonated PBI membranes 

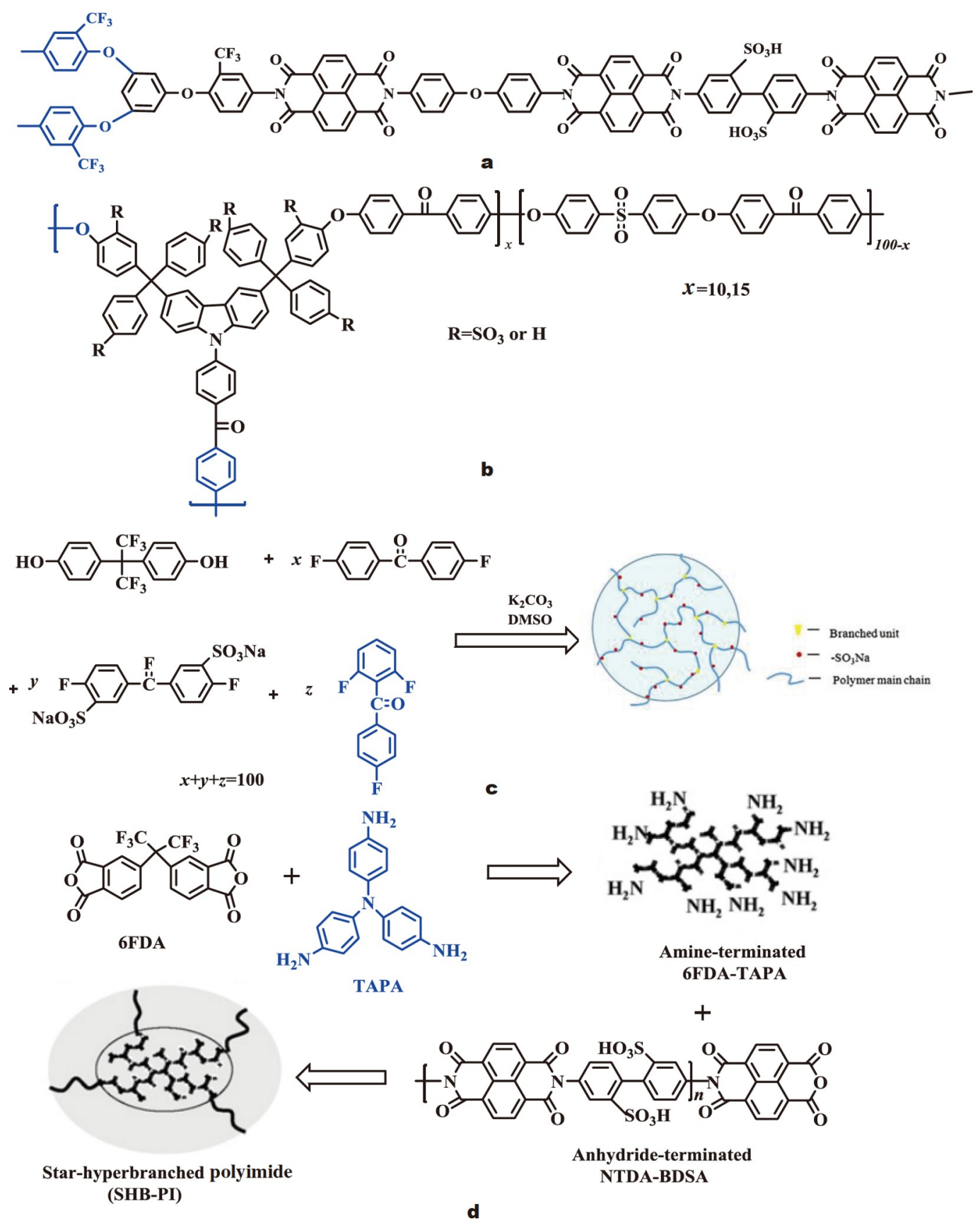

Figure 8 Typical branched structures for PEM application: (a) fluorine-containing branched sPIs; (b) branched sulfonated poly(arylene ether)s containing a carbazole structure; (c) branched sPAEK; (d) synthesis route of sHB-PI. (c) Reprinted with permission from Ref. [153]. Copyright 2013, Elsevier. (d) Reprinted with permission from Ref. [154]. Copyright 2010, Elsevier.

exhibit relatively low proton conductivities because sulfonic acid groups can be neutralized by basic imidazole groups and can form ionic crosslinking $[5,44]$. PA is a kind of nonaqueous solvent to replace water as a medium for proton conduction at increased temperatures [175]. The $-\mathrm{NH}$ and $-\mathrm{N}=\mathrm{C}$ - groups of imidazole rings provide electron-donating to combine with $\mathrm{HO}-\mathrm{PO}_{3} \mathrm{H}_{2}$ via acid-base interactions for proton transportation in PEMs [28]. Therefore, PA-doped PBI membranes are expected to exhibit outstanding proton-conducting capabilities even at high temperatures and anhydrous conditions [176]. Berber et al. [103] prepared PA-doped Bipy-PBI membranes
(Fig. 5a) containing the bipyridine units and basic sites of BIs to absorb PA; as a result, proton conductivity improves. Other acid-absorbing media in a PBI membrane matrix, such as threedimensional network polyacrylamide hydrogels, can occupy additional PA to retain the amount of water to transfer protons in both high- and low-temperature ranges [169]. A high proton conductivity ranging from 0.0159 to $0.104 \mathrm{~S} \mathrm{~cm}^{-1}$ is achieved in the temperature range of 40 to $180^{\circ} \mathrm{C}$, and it remains stable for $120 \mathrm{~h}$. The maximum peak power densities of 200 and $560 \mathrm{~mW} \mathrm{~cm}^{-2}$ are obtained at 80 and $160^{\circ} \mathrm{C}$ under anhydrous conditions, respectively. The improved membrane performance 

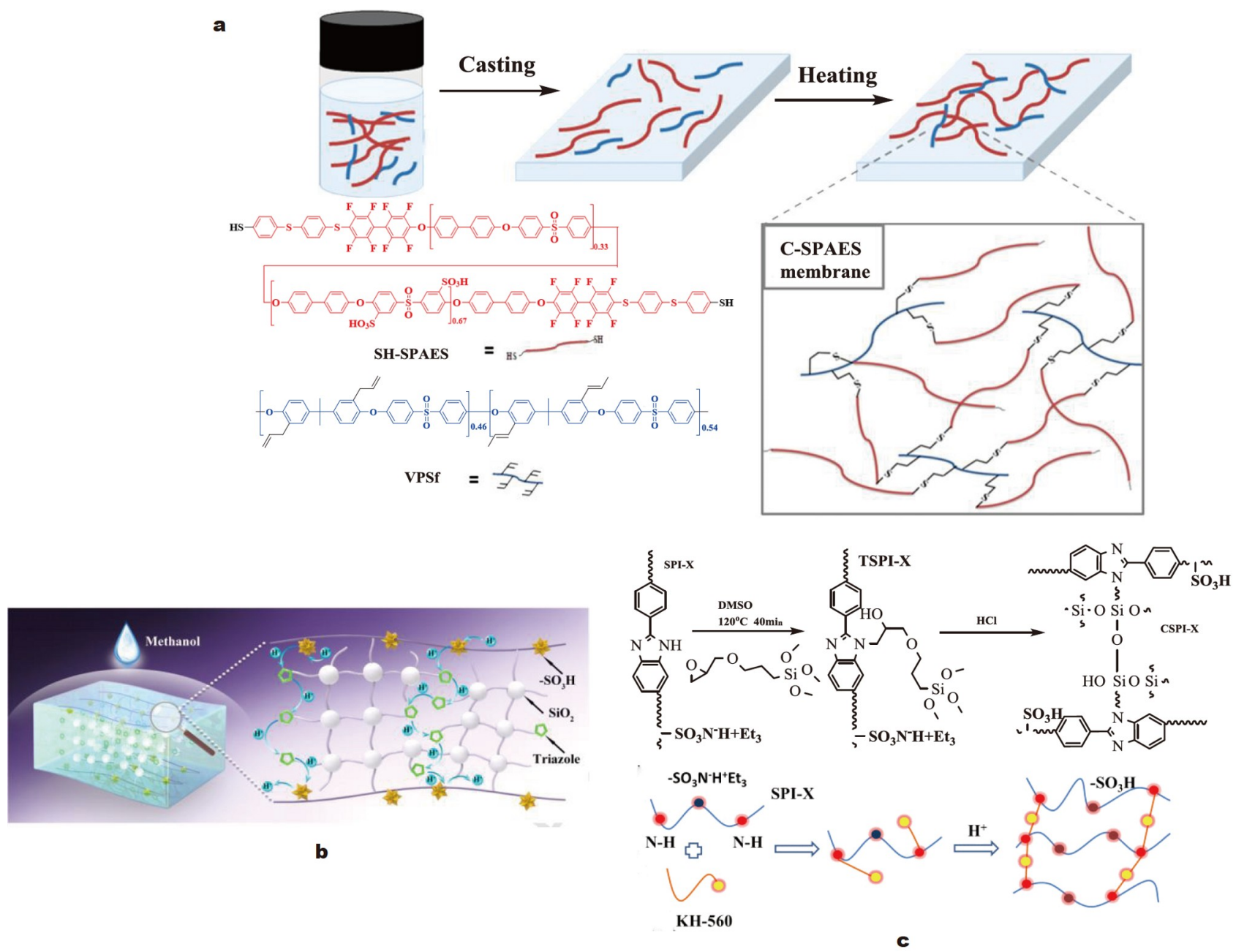

Figure 9 Crosslinking structures in the membrane: (a) end-group-crosslinked sPAES membranes; (b) proton transport mechanism in AMSP/triazolegrafted GT; and (c) crosslinkable sPIs with flexible pendant alkyl side chains containing trimethoxysilyl groups. (a) Reprinted with permission from Ref. [155]. Copyright 2019, Elsevier. (b) Reprinted with permission from Ref. [157]. Copyright 2018, Elsevier. (c) Reprinted with permission from Ref. [158]. Copyright 2017, Elsevier.

with a wide working temperature range may promote their practical applications.

High-temperature circumstances provide high electrode kinetics and simplified water treatment systems for PA-doped PBIs membranes. As proton carriers, PA molecules can conduct protons at high temperatures and low or even zero humidity [176]. Bai et al. [90] investigated the proton conductivities of PA-doped sulfonated PBIs copolymer (sPBI/PA) membranes. Pure sPBIs exhibit a low proton conductivity at $120^{\circ} \mathrm{C}$ and $100 \%$ $\mathrm{RH}$ because of the consumption of $\mathrm{SO}_{3}{ }^{-}$by imidazole groups. However, the sPBI/PA membranes possess desirable proton conductivities, even without external humidification at high temperatures.

\section{Influencing factors}

The proton conductivities of acid-base composite membranes are strongly affected by acid-doping levels, operating temperature, and RH. The proton conductivities of acid-doped membranes increase as environmental humidity and temperature increase. The doping level is determined by the immersion time and adsorption temperature in PA solutions $[53,159,160]$. High PA-doping levels provide more proton carriers and thus pro- mote proton conductivity. However, high acid-doping levels impair the mechanical strengths of membranes because of the plasticizing effect and the dissolution of the polymer matrix [15]. Excessive PA contents lead to severe volume swelling. Therefore, PA-doping levels should be optimized to obtain desirable properties for acid-doped membranes.

The main drawbacks of PA-doped membranes are acid leakage and poor mechanical strength $[5,44]$. Notably, the operating temperature has a contradictory effect on proton conductivity and other properties. For example, increasing working temperature improves electrode kinetics but possibly lowers longterm durability [47]. Humidity is another important factor in proton transfer. Low or zero RH can simplify the water management system of fuel cells. Therefore, PEMs operating at a high temperature and a low RH are highly required.

\section{Modifications of PA-doped membranes}

The rigid skeleton features of PBIs restrict PA doping and hinder their application in HT-PEMs [177]. For PBI-based membranes, effective modification methods are used to enhance fuel cell performance [53,72,92,155]: (1) grafting, (2) branching, (3) crosslinking, and so on. 
Table 2 Tensile strengths, conductivities, and peak power densities of acid-base membranes

\begin{tabular}{|c|c|c|c|c|c|c|}
\hline Type of membrane & $\begin{array}{c}\text { Operational } \\
\text { temperature }\left({ }^{\circ} \mathrm{C}\right)\end{array}$ & $\mathrm{RH}(\%)$ & $\begin{array}{c}\text { Tensile strength } \\
(\mathrm{MPa})\end{array}$ & $\begin{array}{l}\text { Proton conductivity } \\
\qquad\left(\mathrm{S} \mathrm{cm}^{-1}\right)\end{array}$ & $\begin{array}{l}\text { Peak power density } \\
\left(\mathrm{mW} \mathrm{cm}^{-2}\right)\end{array}$ & Ref. \\
\hline $\mathrm{S}^{\mathrm{a}}-\mathrm{PBI}$ & 180 & 0 & 0.804 & 0.326 & - & [3] \\
\hline $\mathrm{C}^{\mathrm{b}}-\mathrm{PBI}-2 \mathrm{BIM}-2 \mathrm{Cl}$ & 200 & 0 & 11.6 & 0.253 & 533 & {$[159]$} \\
\hline C-PBI-AIPA & 120 & 100 & 26 & 0.167 & - & {$[53]$} \\
\hline COPBI & 160 & 0 & $\sim 12$ & 0.073 & 690 & {$[171]$} \\
\hline C-PBI/phenylsulfonated $\mathrm{TiO}_{2}$ & 160 & 5 & 6 & 0.098 & 356 & {$[30]$} \\
\hline $\mathrm{B}^{\mathrm{c}}-\mathrm{PBI}-\mathrm{R}_{2}$ & 160 & 0 & 2.9 & 0.15 & 713 & {$[160]$} \\
\hline B-C-ImOPBI- $x$ & 160 & 0 & 183.3 & 0.089 & 638 & {$[65]$} \\
\hline B-PBI & 180 & 0 & $\sim 8$ & 0.053 & 222 & {$[170]$} \\
\hline $\mathrm{g}^{\mathrm{d}}-\mathrm{c}-\mathrm{XTPPO}^{\mathrm{e}}$ & 180 & 0 & 11.5 & 0.064 & - & {$[66]$} \\
\hline g-PAEK & 190 & 0 & 9 & 0.051 & 61 & {$[167]$} \\
\hline g-PAEK & 200 & 0 & 11.7 & 0.065 & 53 & {$[86]$} \\
\hline g-PSU & 160 & 0 & $>7.9$ & 0.127 & 559 & {$[52]$} \\
\hline g-ImPI-X & 160 & 0 & 5.5 & 0.057 & 551 & {$[172]$} \\
\hline PBI-Sc-X (grafted) & 170 & 0 & 5 & 0.104 & 411.7 & {$[163]$} \\
\hline PBI/PVDF-HFP blend & 160 & 0 & 5.25 & 0.164 & - & {$[164]$} \\
\hline PBI/lignosulfonate (LS) & 160 & 0 & - & 0.187 & - & {$[46]$} \\
\hline PBI/PVT blend & 160 & 0 & - & 0.11 & - & {$[165]$} \\
\hline $\mathrm{PBI} / \mathrm{SiO}_{2}$ blend & 180 & 0 & 34 & 0.1027 & 240 & {$[71]$} \\
\hline $\mathrm{PBI} /$ functionalized $\mathrm{TiO}_{2}$ & 150 & 0 & - & 0.096 & 621 & {$[161]$} \\
\hline PBI/ZrP blend & 180 & 0 & - & 0.2 & - & {$[162]$} \\
\hline OPBI/PAPE blend & 180 & 0 & 1.92 & 0.131 & - & {$[166]$} \\
\hline PPT & 160 & 0 & 12 & 0.099 & 1220 & {$[51]$} \\
\hline Bipy-PBI & 120 & 0 & 17.05 & 0.037 & 779 & {$[103]$} \\
\hline OPBI-AM & 160 & 0 & $\sim 10$ & 0.1 & 560 & {$[169]$} \\
\hline PBIOH-ILs & 170 & 0 & 6.6 & 0.106 & - & {$[82]$} \\
\hline
\end{tabular}

a) S: sulfonated; b) C: crosslinked; c) B: branched; d) g: grafted; e) XTPPO: cross-linked triazole modified poly(2,6-dimethyl-1,4-phenylene oxide) membranes.

\section{(1) Grafting}

$N$-heterocycles provide acidophilic basic units for PA because of acid-base interactions. Thus, polymers become thermally stable by grafting some basic groups (e.g., triazole group); consequently, materials conduct protons at increased temperature via the Grötthuss mechanism [178,179]. Basic heterocyclic groups in polymers can stabilize PA molecules and thus prevent PA leaching from the membrane matrix (Fig. 10a) [167]. For example, sPAEK grafted with 1,2,4-triazole (sPAES) exhibits a proton conductivity of $0.051 \mathrm{~S} \mathrm{~cm}^{-1}$ at $190^{\circ} \mathrm{C}$.

PA-doped PBI possesses a weak benzimidazole $\cdots \cdot \mathrm{H} \cdot \mathrm{H}_{2} \mathrm{PO}_{4}$ interaction because of the weak basicity of BI. Lee et al. [180] prepared quaternary ammonium (QA)-biphosphate ion-paircoordinated polyphenylene (PA-doped QAPOH). The ion-pair coordination in polymers provides $\mathrm{QA}$ hydroxide with relatively strong basicity; thus, a strong $\mathrm{QA}^{+} \cdot \mathrm{H}_{2} \mathrm{PO}_{4}^{-}$interaction occurs. A $\mathrm{PA}$-doped QAPOH membrane shows improved water tolerance, low evaporation of PA loss, and desirable performance of fuel cells. A high peak power density of $800 \mathrm{~mW} \mathrm{~cm}^{-2}$ at $180^{\circ} \mathrm{C}$ is achieved for the PA-doped QAPOH membrane.

Chen et al. [163] grafted the long alkyl side chains with QA groups onto PBI (PBI-Sc-X, Fig. 10b). The strong interactions between QA and biphosphate ion pairs cause PA to remain in the acid-base membranes, thereby improving PA retention capability. The conductivity of PBI-Sc-35 is $0.104 \mathrm{~S} \mathrm{~cm}^{-1}$ at $160^{\circ} \mathrm{C}$, which is 1.6 times higher than that of the ungrafted PBI membrane because of the introduced QA groups. The highest power density of $411.7 \mathrm{~mW} \mathrm{~cm}^{-2}$ is obtained for the PBI-Sc-35 membrane. However, more grafted quaternary groups on the side chains of PBIs can weaken hydrogen-bonding interactions between the main chains, resulting in their low degradation temperature.

Many aromatic hydrocarbon polymers can work as membrane materials in HT-PEMFCs by grafting basic groups. Poly(1vinylimidazole) with basic and acidophilic sites can be grafted on a polysulfone (PSU) backbone via the atom transfer radical polymerization (Fig. 10c) [52]. The self-assembled microstructures of the grafted polymers facilitate fast proton transfer between imidazole groups and PA molecules. The modified membrane exhibits a high proton conductivity of $0.127 \mathrm{~S} \mathrm{~cm}^{-1}$ with a peak power density of $559 \mathrm{~mW} \mathrm{~m}^{-2}$ at $160^{\circ} \mathrm{C}$. Proton conductivity does not decline significantly after $110 \mathrm{~h}$. Wang et al. [94] prepared a series of amino-modified PBIs via grafting ethyl phosphonic acid (EPA) groups on side chains (Fig. 10d). The grafted EPA membrane shows excellent thermal stability and high PA doping ratios because of EPA groups. The proton conductivity of the modified membrane is $0.062 \mathrm{~S} \mathrm{~cm}^{-1}$ at $170^{\circ} \mathrm{C}$ under anhydrous conditions. Chen et al. [172] grafted polyimides with pendant imidazolium groups on side chains (ImPI$\mathrm{X}$, Fig. 10e). The pendant imidazolium groups combined with 


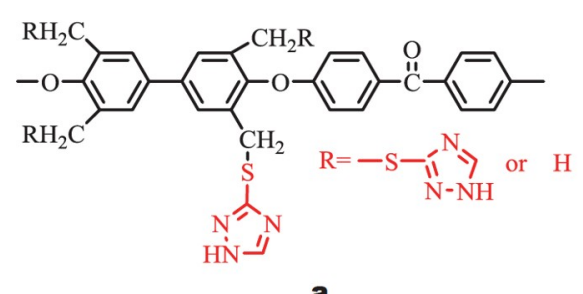

a<smiles>CCC(C(C)Cl)n1ccnc1</smiles>

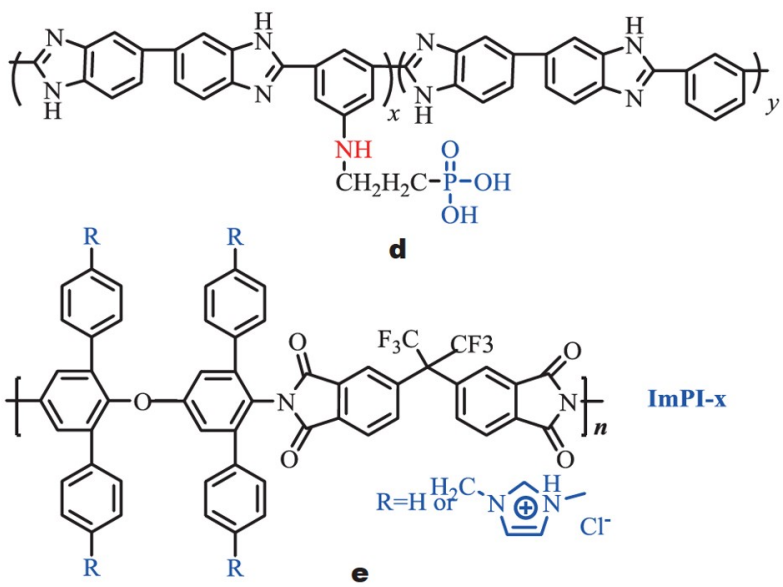

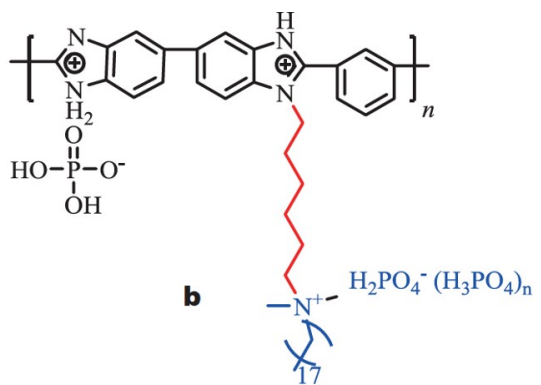


capacity than linear polymers [152]. Gao et al. [65] prepared hyperbranched PBI membranes (ImOPBI) with imidazolium groups on side chains. The tensile strengths and oxidation stabilities of ImOPBI have been improved. The membranes achieve a proton conductivity of $0.089 \mathrm{~S} \mathrm{~cm}^{-1}$ and a peak power density of $638 \mathrm{~mW} \mathrm{~cm}^{-2}$; as such, they meet the potential application requirements of HT-PEMFCs. The proton conductivity of branched polymer membranes is higher than that of linear polymer membranes. Furthermore, high free volumes improve the PA absorption in the membrane matrix because of the interconnected cavities. However, high PA contents inevitably reduce the mechanical properties. Wang et al. [160] introduced 1,3,5-tri(4-carboxyphenyl)benzene (R2) monomers into PBIs to obtain branched star-shaped block PBIs (Fig. 11a). The proton conductivity of the branched PBI membranes is $0.15 \mathrm{~S} \mathrm{~cm}^{-1}$, which is less than $0.03 \mathrm{~S} \mathrm{~cm}^{-1}$ of para-PBI ( $p$-PBI) membrane at $160^{\circ} \mathrm{C}$ under anhydrous conditions. The peak power density of the branched PBI membrane is $713 \mathrm{~mW} \mathrm{~cm}^{-2}$, which is 1.5 times higher than that of the random PBI membrane $\left(483 \mathrm{~mW} \mathrm{~cm}^{-2}\right)$. However, branched structures may damage the mechanical strength of the branched PBI membranes. Obviously, the tensile strength of linear $p$-PBI is $20 \mathrm{MPa}$, which is much higher than that of the branched membrane (below $3 \mathrm{MPa}$ ). Recently, Wang et al. [170] proved that the proton conductivity and free radical resistance of branched OPBI membranes are higher and better than those of the linear OPBI membranes (Fig. 11b). The proton conductivities of all OPBI membranes improve as temperature increases (Fig. 11c). The peak power density $\left(222 \mathrm{~mW} \mathrm{~cm}^{-2}\right)$ of the branched OPBI-R2-6 is higher than that of the linear OPBI membrane $\left(125 \mathrm{~mW} \mathrm{~cm}^{-2}\right)$. The branched OPBI-R2-6 membrane shows a mass loss of $6.9 \%$ after immersion in Fenton's reagent at $80^{\circ} \mathrm{C}$, and this value is significantly lower than that of the linear OPBI membrane $(28.1 \%)$. Furthermore, the existence of ether bonds and bulky rigid branched structures enhances the free radical resistance capability of the branched OPBI membranes. High free volumes improve the PA absorption in the membrane matrix because of the interconnected cavities. However, high PA contents inevitably reduce the mechanical properties.

(3) Crosslinking

The mechanical property and dimensional and oxidative stabilities of PBIs with appropriate crosslinking networks are higher than those of homologous linear polymers [156,182]. The tensile strengths of the crosslinked PBI membranes are above 10.17 $\mathrm{MPa}$, which is higher than that of noncrosslinked membranes (3.33 MPa; Fig. 12a) [183]. Han et al. [184] prepared the crosslinked PBI membranes by using 4,4'-diglycidyl $\left(3,3^{\prime}, 5,5^{\prime}\right.$ tetramethylbiphenyl) epoxy resin (TMBP) as the crosslinker. The crosslinked PBI membranes have high dimensional stability and low swelling at $90^{\circ} \mathrm{C}$, and their proton conductivities at high temperatures are desirable.

PBIs can be modified through ionic crosslinking and covalent
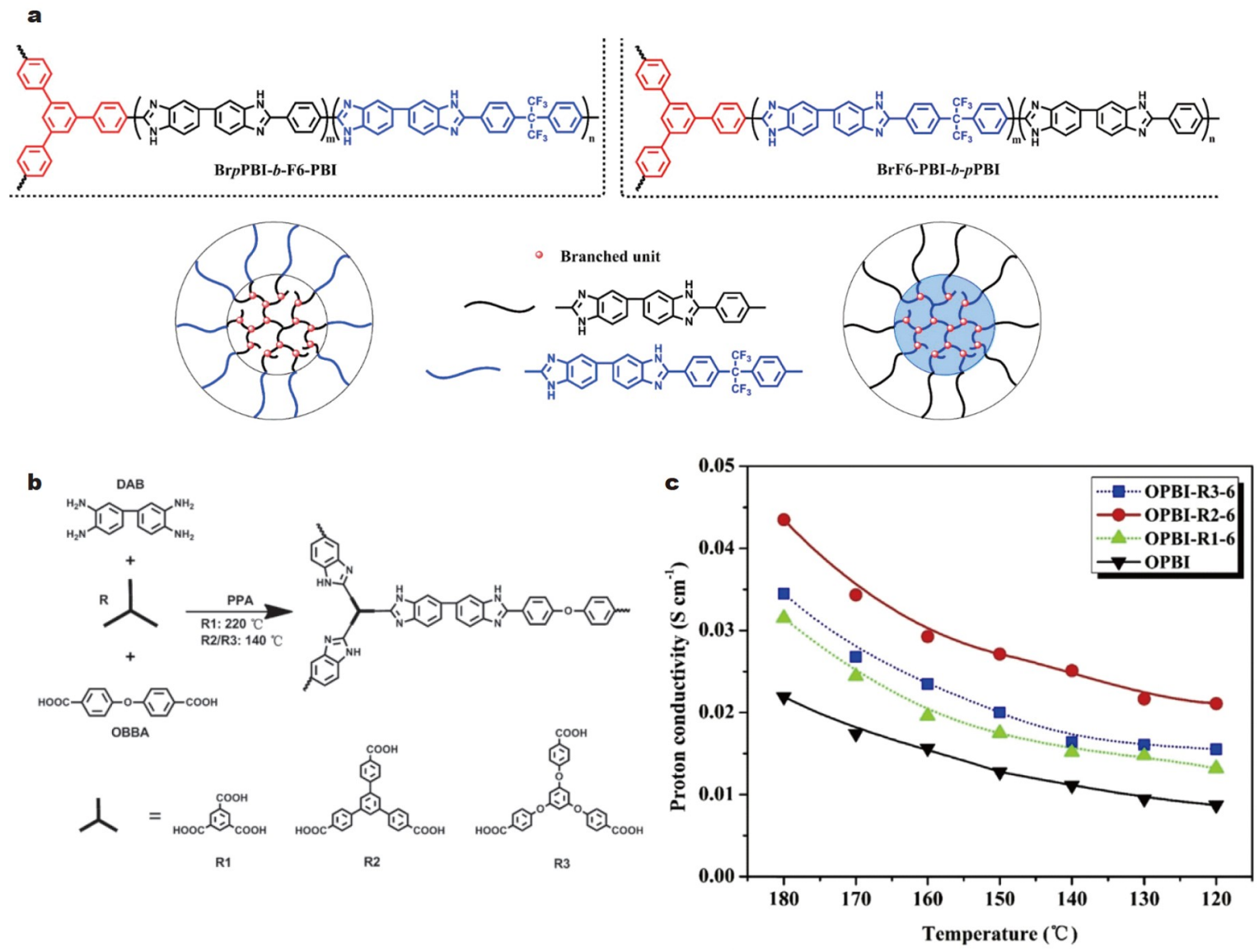

Figure 11 Structures and proton conductivities of branched polymers: (a) branched star-shaped block PBI polymers; (b) R1-, R2-, and R3-based OPBI membranes; (c) temperature-dependent proton conductivity of branched OPBI membranes. (a) Reprinted with permission from Ref. [160]. Copyright 2020, Elsevier. (b, c) Reprinted with permission from Ref. [170]. Copyright 2018, Elsevier. 


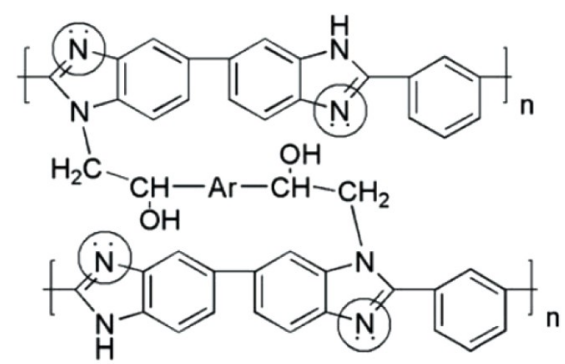<smiles>COc1c(C)cc(-c2cc(C)c(OC=[Zn])c(C)c2)cc1C</smiles>

a
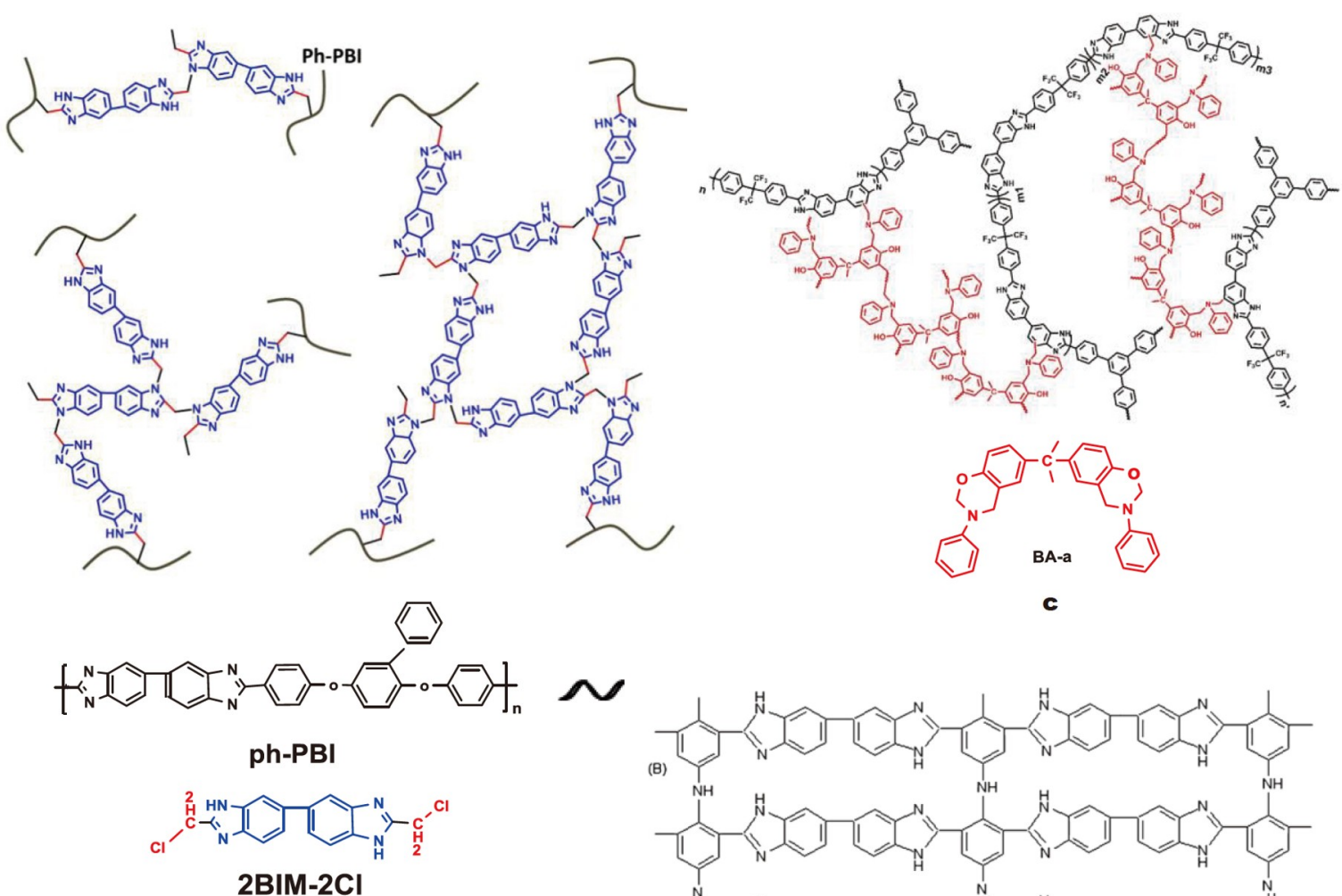

b

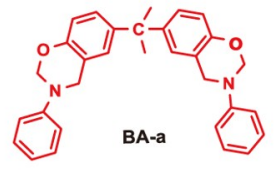

c

Figure 12 PA-doped PBI membranes via crosslinking technology: (a) crosslinked porous PBI membranes with TMBP as the crosslinker; (b) crosslinked PBI membranes with $2 \mathrm{BIM}-2 \mathrm{Cl}$ as the crosslinker; (c) crosslinked PBI with BA-a as the crosslinker; and (d) crosslinked PBI with an inserted AIPA as the crosslinker. (a) Reprinted with permission from Ref. [183]. Copyright 2012, Elsevier. (b) Reprinted with permission from Ref. [159]. Copyright 2020, American Chemical Society. (c) Reprinted with permission from Ref. [171]. Copyright 2019, Elsevier. (d) Reprinted with permission from Ref. [53]. Copyright 2010, Elsevier.

crosslinking. Ionic crosslinking is formed through intermolecular interactions [15]. Covalent crosslinking is performed by reacting functional groups with imidazole groups of PBIs. Thus, the stability of this process is higher than that of ionic crosslinking. However, covalent-crosslinking structures possibly reduce the free volumes within PBIs membranes [22]. Moreover, $\mathrm{N}-\mathrm{H}$ sites at the imidazole rings of PBI backbones as PA absorption sites may be consumed and lost by crosslinker introduction, which ultimately restricts proton transport capability. Therefore, novel crosslinkers, together with more basic sites, should be developed to prepare crosslinked membranes. To improve the proton conductivity and mechanical strength simultaneously, Li et al. [159] synthesized a novel crosslinker containing tetrafunctional bischloro/bibenzimidazole (2BIM$2 \mathrm{Cl}$ ) with self-reaction and inter-reaction capabilities. $2 \mathrm{BIM}-2 \mathrm{Cl}$ increases the acidophilic basic sites of polymers, significantly improving the PA-doping levels (Fig. 12b). The PA-doping levels of crosslinked PBI membranes are higher, and their volume swelling is lower than those of the uncrosslinked PBI membranes. With a $30 \%$ crosslinking degree, PBI membranes show a high proton conductivity of $0.253 \mathrm{~S} \mathrm{~cm}^{-1}$ at $200^{\circ} \mathrm{C}$ without any humidification and a high peak power density of $533 \mathrm{~mW} \mathrm{~cm}^{-2}$ at $160^{\circ} \mathrm{C}$. The crosslinker bis(3-phenyl-3,4-dihydro-2H-1,3-benzoxazinyl) isopropane (BA-a) (Fig. 12c) was used 
to prepare crosslinked and branched PBI membranes and improve poor durability from conventional crosslinking [171]. $\mathrm{BA}$-a can perform crosslinking without consuming any $\mathrm{N}-\mathrm{H}$ sites of PBI backbones. The cell voltage remains almost the same for the crosslinking PBI membranes at $160^{\circ} \mathrm{C}$ for $200 \mathrm{~h}$. The high proton conductivity of $0.073 \mathrm{~S} \mathrm{~cm}^{-1}$ and the peak power density of $690 \mathrm{~mW} \mathrm{~cm}^{-2}$ are achieved. Introducing crosslinkable groups to aniline and carboxylic acid monomers is another promising approach to avoid the consumption of $\mathrm{N}-\mathrm{H}$ sites during the crosslinking process (Fig. 12d). An aniline monomer, 5-aminoisophthalic acid (AIPA) is inserted as an extra basic unit and crosslinker of $\mathrm{BI}$ units, which improve the uptake ratio and mechanical strength of PA [53]. The tensile strength of a $45 \mathrm{wt} \%$ PA-doped poly(benzimidazole- co-aniline) membrane (DPBIA$\mathrm{NI}$ ) is $26 \pm 3 \mathrm{MPa}$, which is higher than those of most PA-doped PBI membranes.

\section{Inorganic-organic composite membranes}

Fillers such as $\mathrm{TiO}_{2}, \mathrm{SiO}_{2}, \mathrm{CB}, \mathrm{ZrO}_{2}, \mathrm{Al}_{2} \mathrm{O}_{3}$, carbon nanotubes, and graphene oxide can be used to improve the hydrolysis resistance, water and acid retention capacity, and electrochemical performance of polymer membrane matrices $[43,185,186]$. When inorganic fillers are introduced into PBIs, water retention improves, and this process is useful for forming hydrogen-bond networks in the membrane matrix because of their intrinsic hydrophilicity. $\mathrm{SiO}_{2}$ is one of the most widely used inorganic additives for PEMs because of its good barrier property toward gases and solvents. Devrim et al. [71] investigated the size effect of $\mathrm{SiO}_{2}$ filler on the structures and properties of the $\mathrm{PBI} / \mathrm{SiO}_{2}$ membrane. The $\mathrm{PBI} / \mathrm{SiO}_{2}$ composite membrane possesses a highly uniform structure because of good dispersibility and compatibility in casting membrane solvents. The tensile strength of the composite membrane is $34 \mathrm{MPa}$, which is higher than that of the pure membrane $(31.2 \mathrm{MPa})$ because of strong interactions between $\mathrm{SiO}_{2}$ and PA or PBI. Furthermore, the $\mathrm{PBI} / \mathrm{SiO}_{2}$ composite membrane shows the highest proton conductivity of $0.1027 \mathrm{~S} \mathrm{~cm}^{-1}$ at $180^{\circ} \mathrm{C}$ under anhydrous conditions, and this value is superior to $0.0944 \mathrm{~S} \mathrm{~cm}^{-1}$ of the pure membrane. The maximum power density of the $\mathrm{PBI} / \mathrm{SiO}_{2}$ membrane also improves to $250 \mathrm{~mW} \mathrm{~cm}^{-2}$ at $165^{\circ} \mathrm{C}$ compared with $185 \mathrm{~mW} \mathrm{~cm}^{-2}$ of the pure PBI membrane.

The hydrophilicity and dispersibility of inorganic nanoparticles can be enhanced by modification and functionalization. Lee et al. [161] prepared sulfophenylated titanium oxide $\left(\mathrm{s}-\mathrm{TiO}_{2}\right)$ via $\mathrm{TiO}_{2}$ functionalization as the blending agent for PBIs. The resulting $\mathrm{s}-\mathrm{TiO}_{2}$-filled membrane exhibits a good dispersion state in the PBI matrix because of sulfophenyl derivatives. The $\mathrm{PBI}$ membrane with fillers achieves a high proton conductivity of $0.096 \mathrm{~S} \mathrm{~cm}^{-1}$ at $150^{\circ} \mathrm{C}$ and a peak power density of $621 \mathrm{~mW} \mathrm{~cm}^{-2}$ under anhydrous conditions, which are higher than the corresponding values of the pure PBI membranes. Other polymers can also be modified by intoducing inorganic fillers. Pandey et al. [187] prepared organic-inorganic composite membranes by using aliphatic-aromatic sPIs and the sulfonated silica precursor (sSP). The nucleophilic attack resistance of the prepared sPIs to water is high by using diamine monomers with high basicity and dianhydride monomers with a low electron affinity. The sSP acts as the water adsorbent and forms a hydrogen-bonding network with sPIs via its functional groups (Fig. 13a).

Agglomeration and low compatibility between inorganic particles and membrane matrix limit the applications of inorganic-organic composite membranes. Inorganic fillers modified with functional groups can alleviate these defects [188,189]. Pandey et al. [190] incorporated multifunctionalized $\left(-\mathrm{SO}_{3} \mathrm{H}\right.$ and $-\mathrm{COOH}$ ) sulfonated propylsilane graphene oxide (sPSGO) in an sPI matrix. The acidic functional groups in sPSGO form strong hydrogen-bonding networks between sPI and sPSGO. The presence of interconnected hydrophobic graphene sheets and sPI chains helps form hydrophobic-hydrophilic phase separation structures for proton conduction in membranes (Fig. 13b). The sPI/sPSGO membrane shows a peak power density of $98.18 \mathrm{~mW} \mathrm{~cm}^{-2}$ at $130^{\circ} \mathrm{C}$ and exhibits a markedly higher proton conductivity $\left(0.096 \mathrm{~S} \mathrm{~cm}^{-1}\right)$ than the sPI membrane without sPSGO $\left(0.06 \mathrm{mS} \mathrm{cm}^{-1}\right)$. Krishnan et al. [30] investigated phenylsulfonated $\mathrm{TiO}_{2}$ particles $\left(\mathrm{s}-\mathrm{TiO}_{2}\right)$ as fillers and crosslinkers for PBI nanocomposite membranes. The covalent crosslinking tends to improve the thermal stability of PBI nanocomposite membranes (Fig. 13c).

Fillers have inherent advantages, such as low costs, good compatibility, and electrochemical properties. Inorganic fillers are widely utilized for PEMs to increase their mechanical strength and proton conductivity. Özdemir et al. [162] introduced $\mathrm{TiO}_{2}, \mathrm{SiO}_{2}$, and the inorganic proton conductor zirconium phosphate $(\mathrm{ZrP})$ into $\mathrm{PBI}$ membranes. All the modified PBI nanocomposite membranes exhibit improved thermal stability with weight losses at around $600^{\circ} \mathrm{C}$. The PBI-ZrP composite membrane shows a high proton conductivity of $0.20 \mathrm{~S} \mathrm{~cm}^{-1}$ at $180^{\circ} \mathrm{C}$. Inorganic additive contents are vital for PEMs. For example, the introduction of $5 \mathrm{wt} \% \mathrm{TiO}_{2}$ into membranes does not enhance proton conductivity because of the agglomeration of excess $\mathrm{TiO}_{2}$.

The introduction of inorganic fillers into membranes increases acid retention properties, resulting in the generation of more proton transportation pathways. Nafion membranes can also be modified with inorganic fillers to improve their water retention ability. Zarrin et al. [73] integrated sulfonic acid-functionalized graphene oxide (F-GO) in Nafion membranes by solution casting. The proton conductivities of the modified Nafion membranes are four times higher than those of the unmodified Nafion membranes at $30 \% \mathrm{RH}$ and $120^{\circ} \mathrm{C}$. F-GO improves water adsorption because of the extremely high surface area and large sulfonated functional groups with an enhanced water retention capacity, thereby facilitating proton diffusion via vehicular mechanisms. Jun et al. [72] prepared an $\mathrm{F}_{-} \mathrm{TiO}_{2}-\mathrm{NT} / \mathrm{Nafion}$ composite membrane by using functionalized titania nanotubes with 3-mercaptopropyl-tri-methoxysilane (MPTMS) as the sulfonated agent. The proton conductivity of the $\mathrm{F}_{-} \mathrm{TiO}_{2}-\mathrm{NT} /$ Nafion composite membrane is higher $\left(0.067 \mathrm{~S} \mathrm{~cm}^{-1}\right)$ than that of the unmodified Nafion membrane $\left(0.012 \mathrm{~S} \mathrm{~cm}^{-1}\right)$ at $120^{\circ} \mathrm{C}$ and $30 \% \mathrm{RH}$.

Various inorganic solid acids have been applied to HT-PEMs to reduce the leaching of unbound acid within PBI membranes. For example, zirconium phytate (ZrPA) can act as an insoluble proton conductor or alternative to PA and water to avoid PA leaching from a membrane matrix thoroughly [191]. Cerium 2,4,6-triphosphono-1,3,5-triazine (CeTPT), a triphonic acid proton conductor, is introduced into the PBI membrane. The CeTPT/PBI membrane shows high proton conductivity at high temperature/low humidity [192]. As one of the most attractive heteropolyacids, phosphotungstic acid $\left(\mathrm{H}_{3} \mathrm{PW}_{12} \mathrm{O}_{40}, \mathrm{HPW}\right)$ can be used as the proton conductor to improve proton conductivity 

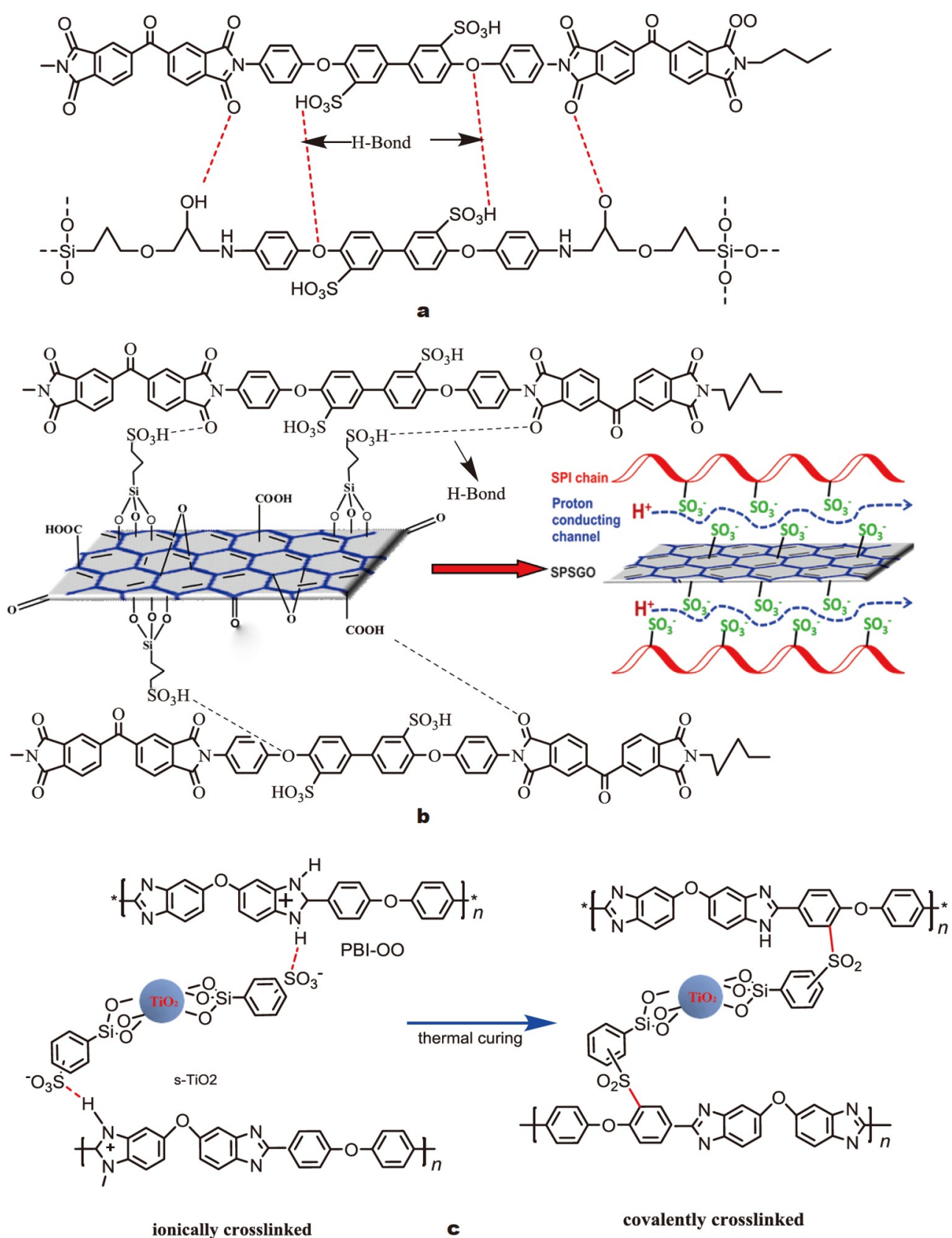

Figure 13 Polymers and proton conduct mechanism for the inorganic-organic hybrid/composite membranes: (a) schematic structures of the sPI/sSP composite membranes; (b) schematic structures of sPI/sPSGO composite membranes and the resulting proton transfer pathways; (c) synthesis of thermally cured membranes. (a) Reprinted with permission from Ref. [187]. Copyright 2013, Royal Society of Chemistry. (b) Reprinted with permission from Ref. [190]. Copyright 2014, American Chemical Society. (c) Reprinted with permission from Ref. [30]. Copyright 2018, Elsevier.

at high temperature/low humidity. Lu et al. [63] prepared HPW self-anchored poly(ether sulfone) (PES)/poly(vinylpyrrolidone) (PVP)-HPW hybrid PEM and found that the hybrid membrane shows high durability and impressive power density $\left(618 \mathrm{~mW} \mathrm{~cm}^{-2}\right)$. However, heteropolyacids are water soluble; as a result, proton conductivity deteriorates. Several strategies have been used to stabilize heteropolyacids within a membrane matrix. Xu et al. [193] introduced four cesium-substituted heteropolyacids (CsPOMo, CsPOW, CsSiOMo, and CsSiOW) into PBI membranes; as such, they have excellent chemical stability, improved conductivity $\left(0.12 \mathrm{~S} \mathrm{~cm}^{-1}\right)$, and enhanced power density $\left(600 \mathrm{~mW} \mathrm{~cm}^{-2}\right)$.

\section{IL-modified membranes}

ILs are purely ionic materials with melting temperatures often around room temperature $[77,186]$. ILs offer many advantages, such as nonvolatility, nonflammability, high ionic conductivity, and excellent chemical and thermal stabilities. Over the years, ILs have been developed as prioritized additives in PEMs to modify polymer membranes [78-80]. They can be immobilized in the polymer backbone and are considered promising proton conductors to solve electrolyte leakage.

ILs can absorb additional PA for proton conduction. Proton transportation within PBI-IL composite membranes at high temperatures is mainly carried out by the Grötthuss mechanism 
[194,195]. Directional protons are transferred through hydrogen-bonded networks by proton jumping among PA molecules, ILs nanoparticles, and imidazole rings of polymer chains [82]. Yi et al. [26] prepared a series of sPEEK/imidazolium-type ILs composite membranes. The thermal stability of the resulting membranes is high at about $340^{\circ} \mathrm{C}$ because of the complex formation between sulfonic acid groups and positively charged imidazolium. The formed hydrophilic ionic domains in a membrane matrix are connected by small ionic channels, and they facilitate proton transport. The sPEEK/ILs composite membrane presents a proton conductivity of $8.3 \times 10^{-3} \mathrm{~S} \mathrm{~cm}^{-1}$ at $170^{\circ} \mathrm{C}$ under anhydrous conditions.

Van de Ven et al. [77] prepared an IL-impregnated PBI membrane that shows a small weight loss in the range of 150$300^{\circ} \mathrm{C}$, and a resulting proton conductivity of $1.86 \mathrm{mS} \mathrm{cm}^{-1}$ at $190^{\circ} \mathrm{C}$ was achieved compared with those of the zero-proton conductivity of Nafion 117. Liu et al. [82] investigated a series of hybrid membranes based on PBI containing hydroxyl groups (PBIOH) and IL-functional silica (ILFS) nanoparticles for HTPEMFCs. PBIOH-ILFS membranes exhibit high tensile strength and excellent thermal stability near $300^{\circ} \mathrm{C}$. When the membrane with 5\% ILFS is immersed in PA for $72 \mathrm{~h}$, its proton conductivity $\left(0.106 \mathrm{~S} \mathrm{~cm}^{-1}\right.$ at $\left.170^{\circ} \mathrm{C}\right)$ is higher than that of the pristine $\mathrm{PBIOH}$ membrane $\left(0.075 \mathrm{~S} \mathrm{~cm}^{-1}\right.$ at $\left.160^{\circ} \mathrm{C}\right)$.

\section{Polymer blend membranes}

Polymer blend electrolytes have many advantages, such as easy preparation and adjustable physical properties [164,196]. The proton conductivity and tensile strength of polymer blend membranes are summarized in Table 3. Lu et al. [197] obtained the proton conductivity of $0.26 \mathrm{~S} \mathrm{~cm}^{-1}$ at $180^{\circ} \mathrm{C}$. Hazarika et al. [164] improved the proton conductivity to $0.164 \mathrm{~S} \mathrm{~cm}^{-1}$ at $160^{\circ} \mathrm{C}$, implying that physical blending including polymerpolymer blending and polymer-nanocomposite blending are feasible methods to retain high proton conductivity and mechanical properties. Furthermore, the surface chemical modifications of PEMs are utilized to form polymer-polymer and polymer-particle hydrogen-bonded networks, which are conducive to not only improving mechanical strength but also enhancing proton conductivity [196-199].

\section{PBI-based blend membranes}

The dimensional and oxidative stabilities of composite membranes obtained by blending PBIs with other polymers and nanoparticles improve compared with those of pristine PBI membranes [147,191,199,200]. Hazarika et al. [164] blended PBIs with poly(vinylidene fluoride-co-hexafluoro propylene) (PVDF-HFP). The mechanical properties, oxidative stability, and proton conductivity of the blend membranes are higher than those of pure PBI membranes. Barati et al. [46] prepared a series of lignosulfonate (LS)/PBI blend membranes (Fig. 14b). Through high LS doping, micropores form within PBI blend membranes, leading to an increased PA-doping level. The highest proton conductivity of $20 \%$ LS-doped PBI blend membrane is about $0.19 \mathrm{~S} \mathrm{~cm}^{-1}$ at $160^{\circ} \mathrm{C}$, which is much higher than $0.03 \mathrm{~S} \mathrm{~cm}^{-1}$ of pure PA-doped PBI membranes. In view of the high proton conductivity and the low cost of LS, the PA-PBI/LS (20 wt\%) membrane is a promising candidate for HT-PEMs.

Porous membranes can highly absorb PA because of a high free volume. Hazarika et al. [165] prepared a porous membrane by blending PBI with poly(1-vinyl-1,2,4-triazole) (PVT, Fig. 14c). The blend membrane is homogeneous and thermally stable up to $300^{\circ} \mathrm{C}$. The morphological characteristics of the formed porous membrane in the PBI/PVT renders it absorb large amounts of PA (Fig. 15); as a result, its proton conductivity is high at $160^{\circ} \mathrm{C}$, i.e., $0.11 \mathrm{~S} \mathrm{~cm}^{-1}$, which is much higher than $0.04 \mathrm{~S} \mathrm{~cm}^{-1}$ of the pure PBI membrane.

The construction of microporous structures within polymer membranes is an effective way of improving the PA-doping level and acid retention ability because of a high free volume. The presence of micropores, good pore size distribution, and extensive interconnected capillary channels in membranes are advantageous for highly conductive PEM applications [201]. Geng et al. [202] prepared a symmetric sponge-like porous PBI membrane with thousands of micron-sized cells separated by ultrathin walls. Pore walls provide multiple barriers to avoid fuel crossover. Therefore, a desirable fuel cell performance is achieved because of high acid-doping levels.

Hydrogen-bonding interactions positively affect chemical stability and other electrochemical performances. Koyilapu et al. [166] blended OPBI with poly(aminophosphonate ester) (PAPE,

Table 3 Tensile strengths, conductivities, and peak power densities of polymer blend membranes

\begin{tabular}{|c|c|c|c|c|c|c|}
\hline Type of membrane & $\begin{array}{c}\text { Operational } \\
\text { temperature }\left({ }^{\circ} \mathrm{C}\right)\end{array}$ & $\begin{array}{c}\text { Relative } \\
\text { humidity (\%) }\end{array}$ & $\begin{array}{c}\text { Tensile strength } \\
(\mathrm{MPa})\end{array}$ & $\begin{array}{l}\text { Proton conductivity } \\
\left(\mathrm{S} \mathrm{cm}^{-1}\right)\end{array}$ & $\begin{array}{l}\text { Peak power density } \\
\left(\mathrm{mW} \mathrm{cm}^{-2}\right)\end{array}$ & Ref. \\
\hline $\mathrm{PBI} / \mathrm{LS}$ & 160 & 0 & - & 0.187 & - & {$[46]$} \\
\hline PBI/PVDF-HFP & 160 & 0 & 5.25 & 0.164 & - & {$[164]$} \\
\hline $\mathrm{PBI} / \mathrm{PVT}$ & 160 & 0 & - & 0.11 & - & {$[165]$} \\
\hline OPBI/PAPE & 180 & 0 & 1.92 & 0.131 & - & {$[166]$} \\
\hline CsPOW/PBI & 150 & 0 & - & 0.1 & 0.59 & [193] \\
\hline CsPOMo/PBI & 150 & 0 & - & 0.12 & 0.63 & {$[193]$} \\
\hline CsSiOW/PBI & 150 & 0 & - & 0.057 & 0.51 & {$[193]$} \\
\hline $\mathrm{CsSiOMo/PBI}$ & 150 & 0 & - & 0.051 & 0.48 & [193] \\
\hline PES-PVP/PTFE & 180 & 0 & 6.5 & 0.26 & 607 & {$[197]$} \\
\hline PES-PVP & 180 & 0 & 1.25 & 0.149 & - & {$[198]$} \\
\hline PSU-PVP & 160 & 0 & 2.6 & 0.065 & - & {$[198]$} \\
\hline PEK-c-PVP & 160 & 0 & 2 & 0.061 & - & {$[198]$} \\
\hline sPBI/sIGO & 120 & 10 & 103.2 & 0.0058 & 400 & [199] \\
\hline
\end{tabular}




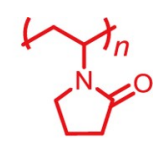

(PVP)

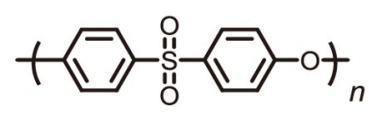

(PES)

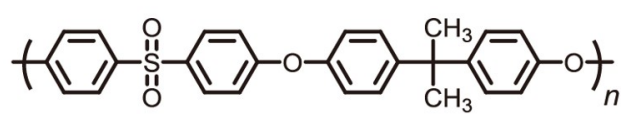

(PSU)<smiles>CC(C)(C)C(=O)Oc1ccc(C2(c3ccc(Oc4ccc(C(=O)c5ccc(C(C)(C)C)cc5)cc4)cc3)OC(=O)c3ccccc32)cc1</smiles>
(PEK-c)<smiles>CC(C(=O)O)C(=O)c1ccc(C(CO)C(CO)C(=O)O)c(O)c1</smiles>

c<smiles></smiles>
mPBI<smiles></smiles>

OPBI

\section{d}

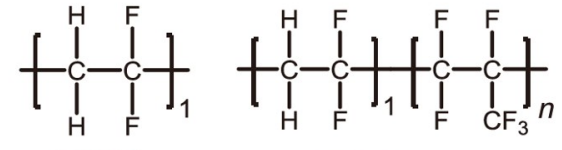

(PHFP)<smiles></smiles>

mPBI<smiles>CC(C)(C)CC(n1cncn1)C(C)(C)C</smiles>

PVT<smiles>CCOP(=O)(OCC)C(NCCNC(F)(F)F)c1ccc(C(C(C)(C)C)P(=O)(OCC)OCC)cc1</smiles>

PAPE

Figure 14 Polymer membranes via blending: (a) structures of polymer blend membranes based on PVP; (b) structures of PBI blended with LS; (c) structures of mPBI blended with PVT; and (d) structures of OPBI blended with PAPE.

Fig. 14d). Hydrogen-bonding interactions form between the $\mathrm{N}-\mathrm{H}$ of OPBI and the phosphonate ester groups of PAPE, and improve the PA-doping levels and tensile properties of membranes. The OPBI/PAPE membrane with a $75 / 25$ blending ratio shows a maximum conductivity of $0.131 \mathrm{~S} \mathrm{~cm}^{-1}$ at $180^{\circ} \mathrm{C}$, which is much higher than that of the pure OPBI membrane $\left(0.055 \mathrm{~S} \mathrm{~cm}^{-1}\right)$. The conductivities of $50 / 50$ and $90 / 10$ blend membranes are much lower than those of $75 / 25$ blend membranes because of the crystalline morphologies within membranes. A certain degree of matrix crystallization leads to an increase in ionic conductivity. However, the excess crystallinity of the membrane matrix impairs the absorption of PA molecules and the network formation of proton-conducting pathways $[203,204]$.

Other polymer-based blend membranes

PVP is industrially used in many areas because of its low cost and simple synthesis [63]. The characteristic of $N$-heterocycles in polymers is good to absorb PA for proton conduction in PEMs. However, the hydrophilic PVP tends to dissolve in water. Therefore, blending PVP with other water insoluble polymers is efficient (e.g., PES [197,205]). The tensile strength of PVP membranes blended with aromatic polymers is higher than that of those blended with aliphatic polymers. PES, PSU, polyetherketone-cardo (PEK-c), polyvinylidene fluoride (PVDF), and poly(vinylidene fluoride-co-hexafluoropropylene) (PHFP) are used to blend with PVP (Fig. 14a). Ren et al. [198] investigated the properties of various polymer-polymer blends based on PVP. PES-PVP, PSU-PVP, and PEK-c-PVP blend membranes show low volume swelling, high acid-doping level, high proton conductivity, and high mechanical strength. Increasing the PVP contents improves PA absorption in membranes because of the improved acidophilic capability by introduced intrinsic $N$-heterocycles.

Sulfonated polymers tend to swell in a hydration environment, resulting in poor mechanical performance, especially at elevated temperatures. Low-swelling aromatic hydrocarbon polymers, such as PBTs and PBIs, can work as reinforced components to restrain membrane swelling and promote stable proton conduction. Xiao and his group [206] found that sPBT membranes have low swelling even at high temperatures, possibly because of acid-base interactions between sulfonic acid groups and BT groups. The high dimensional stability of sulfonated poly(arylene thioether phosphine oxide) (sPTPO)/sPBT blend membrane remains even at $100^{\circ} \mathrm{C}$. Yuan et al. [207] prepared lowswelling-ratio blend membranes based on the synthesized polyimide (sPI) with a $100 \%$ sulfonation degree. Furthermore, PVDF was utilized as the blending agent to suppress the water swelling of sPI in hydrated membranes. The swelling ratios of the resulting sPI/PVDF blend membranes improve to $<3 \%$ 

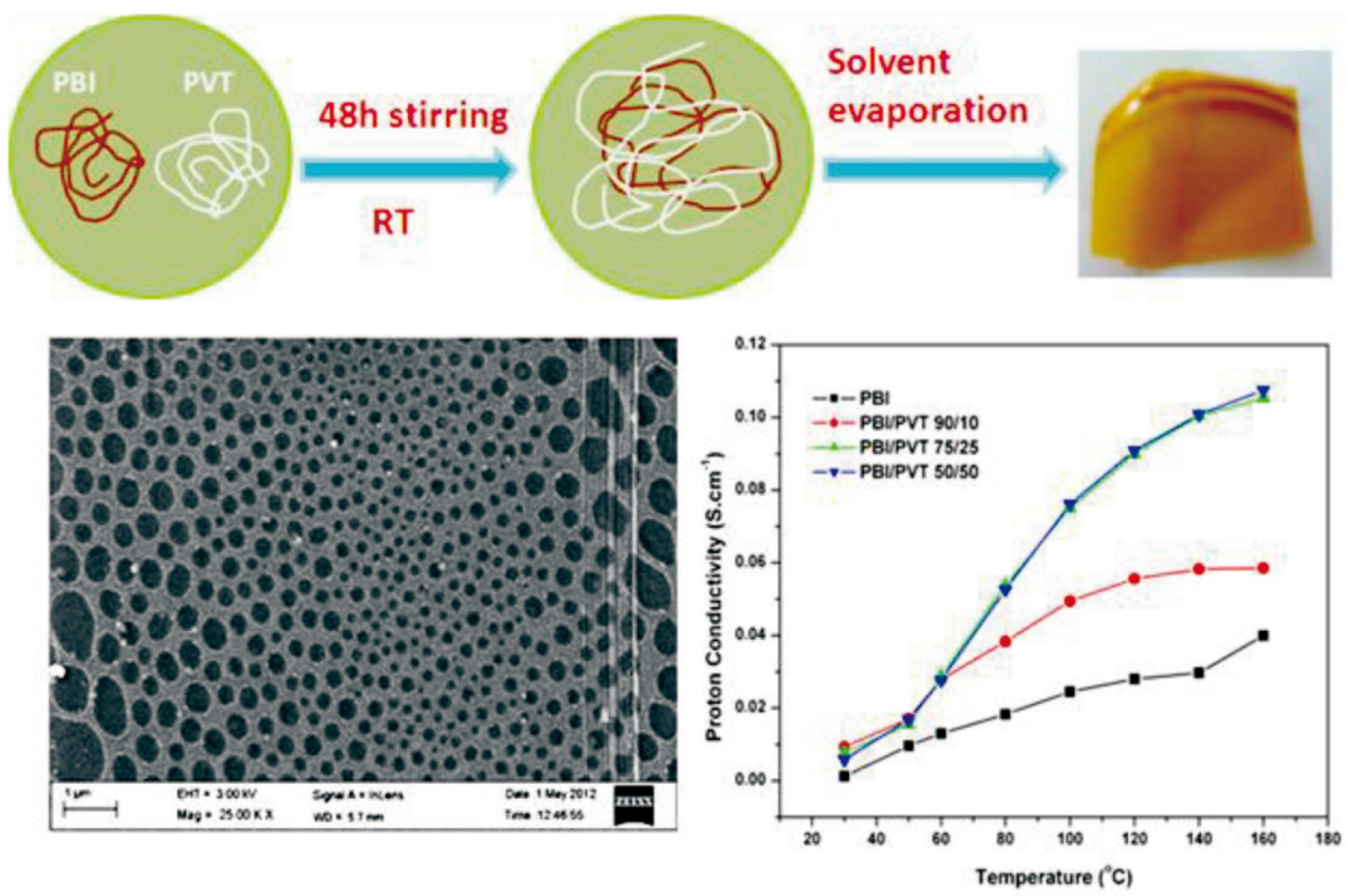

Figure 15 Blend of PBI and PVT and the resulting porous morphology and proton conductivity. Reprinted with permission from Ref. [165]. Copyright 2012, American Chemical Society.

compared with that of $18 \%$ of Nafion 117 because of the crystalline PVDF. The conductivity of sPI/PVDF blend membranes is higher and its film processing occurs more easily than those of Nafion 117.

\section{CONCLUSIONS AND PERSPECTIVES}

HT-PEMFCs provide enhanced electrode kinetics and show more tolerance to fuel impurities, in contrast to conventional LT-PEMFCs. HT-PEMs can be utilized to replace Nafion membranes because of their outstanding performance advantages. Efforts have been devoted to the preparation of membrane materials for HT-PEMFCs with high conductivity, low cost, and high durability. In this review, an overview of the recent developments in polymer-based PEMs for high-temperature fuel cell applications is presented. Structural architectures, including main-chain backbone fabrication, side-group/chain engineering, and compositing/blending strategies, are discussed in detail. For the main-chain backbone fabrication, suitable moieties include BIs, BT, imide, and EEK moieties. Their synthesis, performance characteristics, and influencing factors on PEMs based on sulfonated polymers are summarized. Side-group/chain engineering, including grafting, branching, and crosslinking, is effective in achieving desirable membrane performances for high-temperature applications. The compositing/blending modification methods of polymers for PEMs are also effective in obtaining high PA-doping levels and superior mechanical properties. The main-chain backbone fabrication offers high chemical and thermal stability, but proton conductivity cannot be equivalent to those of Nafion membranes. The stability of side-group/ chain-engineered polymers with pendant acid groups is more stable against hydrolysis, and their proton conductivity is higher than those of the main chain polymers. Compositing/blending eliminates the significant requirements of high humidity for rapid proton transfer in HT-PEMs because of the appearance of PA (proton carriers). However, the inevitable leaching of PA likely damages membrane durability and electrochemical performance to some extent.

Sulfonated polymers provide high proton conductivity and excellent mechanical properties at increased temperatures. High sulfonation degree helps increase proton conductivity. However, excessive sulfonic acid groups result in high hydrophilicity, and the resulting membranes easily swell in water or even dissolve in hot water. The trade-off between proton conductivity and mechanical properties should be considered to achieve the structural architectures of PEMs. Side-chain-type sulfonated polymers, such as polyimides and PEEK, have been widely explored. Furthermore, studies have introduced sulfonic acid groups through side-chain engineering by grafting, branching, and crosslinking to modify PEMs.

PA-doped PBIs are one of the main types of membrane materials for high-temperature applications. Grafting and crosslinking approaches have been widely used to modify traditional PBIs. Acid-base composite membranes based on grafted basic groups have also attracted considerable attention because of their low cost and easy functionalization. Acid-base composite membranes, especially PA-doped polymer membranes are still the dominant parts in contrast to other sulfonated polymer electrolytes operating at temperatures above $120^{\circ} \mathrm{C}$. PBI is the most successful polymer membrane material for applications at high temperatures, and more functional units are used to be incorporated in PBI to improve membrane performance. Aryl ether-free polymer-based HT-PEMs and PA-grafted HT-PEMs have also been used as excellent electrolytes.

However, mechanical properties decrease as the doping amounts of PA increase. Acid leaching and PA retention capabilities are important challenges operating at increased tem- 
peratures. Inorganic filler introduction is an effective method to improve proton conductivity because of the hygroscopicity of nanofillers. However, interactions between a membrane matrix and fillers are still unclear. The internal mechanism should be investigated in detail instead of simply focusing on the improvement of the PEM performance. Inorganic fillers easily aggregate in the membrane matrix, thereby limiting organicinorganic membranes. For acid-doping membranes, acid leakage and PA evaporation at high temperatures are obvious issues that restrain the application of HT-PEMFCs. Some effective approaches have alleviated the mentioned adverse phenomenon. Grafting PA and adopting other proton carriers (e.g., HPW and phytic acid) into polymers are both practical advanced technologies as stable polymer-based electrolyte materials for proton conduction at high temperatures.

With the rapid development of fuel cells in recent years, ideal membrane materials should be established. The key requirements of polymer-based PEMs for HT-PEMFCs include the following: (1) high proton conductivity at high temperature/low humidity; (2) low fuel permeability toward avoiding a fuel crossover; (3) satisfactory mechanical properties while introducing a proton conduction medium; (4) long-term durability and excellent physicochemical stability; (5) lower material cost and good processability; and (6) simple membrane preparation processes with no pollution.

Although the modification of PEMs has been greatly enhanced, the development of advanced polymer-based PEMs for HT-PEMFCs remains challenging. Further research should address the following significant and fundamental issues to improve the properties.

First, the intrinsic structure-property relationships of polymer-based PEMs for high-temperature fuel cell applications should be further explored, especially the relationship between microscopic morphology and macroscopic performance, including main-chain backbone fabrication, side-group/chain engineering, compositing/blending, and crosslinking methods. The macroscopic properties of PEMs, such as thermal properties, water uptake, dimensional swelling, mechanical properties, and proton conductivity, are greatly affected by their microstructures. For example, the diameters of ionic clusters in the atomic force microscopy measurements of PEMs can be changed by incorporating different units. Morphological changes and cluster diameters are possibly responsible for membrane swelling. The architectural design of PEMs based on structureproperty relationships will be highly significant for the future development of advanced polymer PEMs for high-temperature fuel cell applications.

Second, the underlying mechanisms responsible for the ability of PEMs to endure high temperatures for high-temperature fuel cell applications are unclear, and few related studies have been performed. The mechanisms should be studied by incorporating different units into polymer-based PEMs. The combination of computational chemistry and the experiments of polymer-based PEMs should also be developed as an effective way to study the high-temperature mechanisms of polymer-based PEMs.

Third, a combination of two or three approaches, including main-chain backbone fabrication, side-group/chain engineering, compositing/blending, and crosslinking, will be expected to further improve the PEM properties. Combinatorial methods will be new strategies to develop next-generation PEM materials for high-temperature fuel cell applications.
To address these challenges, researchers should conduct cooperative studies in various fields. Efforts should be devoted to investigating PEM materials to develop their applications in HTPEMFCs.

\section{Received 12 August 2021; accepted 3 November 2021;} published online 24 December 2021

1 Tao Z, Wang C, Zhao X, et al. Progress in high-performance anion exchange membranes based on the design of stable cations for alkaline fuel cells. Adv Mater Technol, 2021, 6: 2001220

2 Escorihuela J, Olvera-Mancilla J, Alexandrova L, et al. Recent progress in the development of composite membranes based on polybenzimidazole for high temperature proton exchange membrane (PEM) fuel cell applications. Polymers, 2020, 12: 1861

3 Wang L, Bliznakov S, Isseroff R, et al. Enhancing proton exchange membrane fuel cell performance via graphene oxide surface synergy. Appl Energy, 2020, 261: 114277

4 Wang Y, Ruiz Diaz DF, Chen KS, et al. Materials, technological status, and fundamentals of PEM fuel cells-A review. Mater Today, 2020, 32: $178-203$

5 Shin DW, Guiver MD, Lee YM. Hydrocarbon-based polymer electrolyte membranes: Importance of morphology on ion transport and membrane stability. Chem Rev, 2017, 117: 4759-4805

6 Wang C, Tao Z, Zhao X, et al. Poly(aryl ether nitrile)s containing flexible side-chain-type quaternary phosphonium cations as anion exchange membranes. Sci China Mater, 2019, 63: 533-543

7 Nakabayashi K, Higashihara T, Ueda M. Polymer electrolyte membranes based on cross-linked highly sulfonated multiblock copoly (ether sulfone)s. Macromolecules, 2010, 43: 5756-5761

8 Yamazaki K, Wang G, Tanaka M, et al. Sulfonated block-graft copolyimide for high proton conductive and low gas permeable polymer electrolyte membrane. J Power Sources, 2012, 216: 387-394

9 Yao Y, Lin Z, Li Y, et al. Superacidic electrospun fiber-nafion hybrid proton exchange membranes. Adv Energy Mater, 2011, 1: 1133-1140

10 Chen N, Hu C, Wang HH, et al. Poly(alkyl-terphenyl piperidinium) ionomers and membranes with an outstanding alkaline-membrane fuel-cell performance of $2.58 \mathrm{~W} \mathrm{~cm}^{-2}$. Angew Chem Int Ed, 2021, 60 : 7710-7718

11 Wang C, Tao Z, Zhou Y, et al. Anion exchange membranes with eight flexible side-chain cations for improved conductivity and alkaline stability. Sci China Mater, 2020, 63: 2539-2550

12 Chen N, Wang HH, Kim SP, et al. Poly(fluorenyl aryl piperidinium) membranes and ionomers for anion exchange membrane fuel cells Nat Commun, 2021, 12: 2367

13 Wang YJ, Qiao J, Baker R, et al. Alkaline polymer electrolyte membranes for fuel cell applications. Chem Soc Rev, 2013, 42: 5768-5787

14 Gu F, Dong H, Li Y, et al. Highly stable N3-substituted imidazoliumbased alkaline anion exchange membranes: Experimental studies and theoretical calculations. Macromolecules, 2013, 47: 208-216

$15 \mathrm{Su} \mathrm{J}, \mathrm{Pu} \mathrm{H}$, Chang $\mathrm{Z}$, et al. A facile crosslinking method of polybenzimidazole with sulfonyl azide groups for proton conducting membranes. Polymer, 2012, 53: 3587-3593

16 Andújar JM, Segura F. Fuel cells: History and updating. A walk along two centuries. Renew Sustain Energy Rev, 2009, 13: 2309-2322

17 Park CH, Lee CH, Guiver MD, et al. Sulfonated hydrocarbon membranes for medium-temperature and low-humidity proton exchange membrane fuel cells (PEMFCs). Prog Polym Sci, 2011, 36: 1443-1498

18 Peckham TJ, Holdcroft S. Structure-morphology-property relationships of non-perfluorinated proton-conducting membranes. Adv Mater, 2010, 22: 4667-4690

19 Grubb Jr WT. General Electric Company. Fuel cell. US Patent, 2913511, 1959-11-17

20 Rikukawa M, Sanui K. Proton-conducting polymer electrolyte membranes based on hydrocarbon polymers. Prog Polym Sci, 2000, 25: 1463-1502

21 Chandan A, Hattenberger M, El-kharouf A, et al. High temperature (HT) polymer electrolyte membrane fuel cells (PEMFC) - A review. J 
Power Sources, 2013, 231: 264-278

22 Yu TL. Overview of electrochemical polymer electrolyte membranes. In: Fang J, Qiao J, Wilkinson DP, et al. (EDs). Electrochemical Polymer Electrolyte Membranes, Florid: CRC press, 2016

23 Sun X, Simonsen SC, Norby T, et al. Composite membranes for high temperature PEM fuel cells and electrolysers: A critical review. Membranes, 2019, 9: 83

24 Bose S, Kuila T, Nguyen TXH, et al. Polymer membranes for high temperature proton exchange membrane fuel cell: Recent advances and challenges. Prog Polym Sci, 2011, 36: 813-843

25 Ma YL, Wainright JS, Litt MH, et al. Conductivity of PBI membranes for high-temperature polymer electrolyte fuel cells. J Electrochem Soc, 2004, 151: A8

26 Yi S, Zhang F, Li W, et al. Anhydrous elevated-temperature polymer electrolyte membranes based on ionic liquids. J Membrane Sci, 2011, 366: $349-355$

27 Grot W. Perfluorierte Kationenaustauscher Polymere. Chemie Ingenieur Technik. 1975, 47: 617

$28 \mathrm{Li}$ Q, Jensen JO, Savinell RF, et al. High temperature proton exchange membranes based on polybenzimidazoles for fuel cells. Prog Polym Sci, 2009, 34: 449-477

29 Li Q, Aili D, Yang J, et al. Polybenzimidazoles: Synthesis, characterizations and applications in form of membranes. Mater Sci Res J, 2012, 6: $219-273$

30 Krishnan NN, Lee S, Ghorpade RV, et al. Polybenzimidazole (PBIOO) based composite membranes using sulfophenylated $\mathrm{TiO}_{2}$ as both filler and crosslinker, and their use in the HT-PEM fuel cell. J Membrane Sci, 2018, 560: 11-20

31 Chen CY, Garnica-Rodriguez JI, Duke MC, et al. Nafion/polyaniline/ silica composite membranes for direct methanol fuel cell application. J Power Sources, 2007, 166: 324-330

32 Taherkhani Z, Abdollahi M, Sharif A. Proton conducting porous membranes based on poly(benzimidazole) and poly(acrylic acid) blends for high temperature proton exchange membranes. Solid State Ion, 2019, 337: 122-131

33 Polino $\mathrm{M}$, Portugal CAM, Le The $\mathrm{H}$, et al. Enhanced protein crystallization on nafion membranes modified by low-cost surface patterning techniques. Cryst Growth Des, 2020, 20: 2174-2186

34 Song Y, Li X, Xiong J, et al. Electrolyte transfer mechanism and optimization strategy for vanadium flow batteries adopting a nafion membrane. J Power Sources, 2020, 449: 227503

35 Jiang $\mathrm{B}, \mathrm{Wu} \mathrm{L}, \mathrm{Yu} \mathrm{L}$, et al. A comparative study of nafion series membranes for vanadium redox flow batteries. J Membrane Sci, 2016, 510: $18-26$

36 Chien HC, Tsai LD, Huang CP, et al. Sulfonated graphene oxide/ nafion composite membranes for high-performance direct methanol fuel cells. Int J Hydrogen Energy, 2013, 38: 13792-13801

37 Singh A, Mukherjee R, Banerjee S, et al. Sulfonated polytriazoles from a new fluorinated diazide monomer and investigation of their proton exchange properties. J Membrane Sci, 2014, 469: 225-237

38 Xie T. Tunable polymer multi-shape memory effect. Nature, 2010, 464: $267-270$

39 Haider R, Wen Y, Ma ZF, et al. High temperature proton exchange membrane fuel cells: Progress in advanced materials and key technologies. Chem Soc Rev, 2021, 50: 1138-1187

40 Han X, Pang J, Liu D, et al. Novel branched sulfonated poly(arylene ether)s based on carbazole derivative for proton exchange membrane. Int J Hydrogen Energy, 2020, 45: 4644-4652

$41 \mathrm{Wu} \mathrm{Z}$, Sun G, Jin W, et al. Nafion ${ }^{\circledR}$ and nano-size $\mathrm{TiO}_{2}-\mathrm{SO}_{4}{ }^{2-}$ solid superacid composite membrane for direct methanol fuel cell. J Membrane Sci, 2008, 313: 336-343

42 Park CH, Lee SY, Hwang DS, et al. Nanocrack-regulated self-humidifying membranes. Nature, 2016, 532: 480-483

43 He R, Li Q, Bach A, et al. Physicochemical properties of phosphoric acid doped polybenzimidazole membranes for fuel cells. J Membrane Sci, 2006, 277: 38-45

44 Zhang H, Shen PK. Recent development of polymer electrolyte membranes for fuel cells. Chem Rev, 2012, 112: 2780-2832

45 Araya SS, Zhou F, Liso V, et al. A comprehensive review of PBI-based high temperature PEM fuel cells. Int J Hydrogen Energy, 2016, 41: 21310-21344

46 Barati S, Abdollahi M, Mehdipourghazi M, et al. High temperature proton exchange porous membranes based on polybenzimidazole/ lignosulfonate blends: Preparation, morphology and physical and proton conductivity properties. Int J Hydrogen Energy, 2019, 44: 30440-30453

47 Oono Y, Fukuda T, Sounai A, et al. Influence of operating temperature on cell performance and endurance of high temperature proton exchange membrane fuel cells. J Power Sources, 2010, 195: 1007-1014

48 Bayer T, Cunning BV, Selyanchyn R, et al. High temperature proton conduction in nanocellulose membranes: Paper fuel cells. Chem Mater, 2016, 28: 4805-4814

49 Authayanun S, Im-orb K, Arpornwichanop A. A review of the development of high temperature proton exchange membrane fuel cells. Chin J Catal, 2015, 36: 473-483

50 Kumar A, Su HC, Chen YS, et al. Effect of catalyst layer with zeolite on the performance of a proton exchange membrane fuel cell operated under low-humidity conditions. Int J Hydrogen Energy, 2021, 46 15878-15886

51 Bai H, Peng H, Xiang Y, et al. Poly(arylene piperidine)s with phosphoric acid doping as high temperature polymer electrolyte membrane for durable, high-performance fuel cells. J Power Sources, 2019, 443: 227219

52 Bai $\mathrm{H}$, Wang $\mathrm{H}$, Zhang J, et al. High temperature polymer electrolyte membrane achieved by grafting poly(1-vinylimidazole) on polysulfone for fuel cells application. J Membrane Sci, 2019, 592: 117395

53 Bhadra S, Kim NH, Lee JH. A new self-cross-linked, net-structured, proton conducting polymer membrane for high temperature proton exchange membrane fuel cells. J Membrane Sci, 2010, 349: 304-311

54 Shin DW, Lee SY, Kang NR, et al. Durable sulfonated poly(arylene sulfide sulfone nitrile)s containing naphthalene units for direct methanol fuel cells (DMFCs). Macromolecules, 2013, 46: 3452-3460

55 Ghorai A, Roy S, Das S, et al. Chemically stable sulfonated polytriazoles containing trifluoromethyl and phosphine oxide moieties for proton exchange membranes. ACS Appl Polym Mater, 2020, 2: $2967-$ 2979

56 Ahmed Z, Charradi K, Alsulami QA, et al. Physicochemical characterization of low sulfonated polyether ether ketone/smectite clay composite for proton exchange membrane fuel cells. J Appl Polym Sci, 2020, 138: 49634

57 Amari S, Ando S, Miyanishi S, et al. Effect of a sulfonated benzothiadiazole unit on the morphology and ion conduction behavior of a polymer electrolyte membrane. Ind Eng Chem Res, 2018, 57: 1609516102

58 Wang S, He F, Weng Q, et al. Synthesis and characterization of a novel crosslinkable side-chain sulfonated poly(arylene ether sulfone) copolymer proton exchange membranes. RSC Adv, 2020, 10: 24772-24783

59 Soumeur MA, Gasbaoui B, Abdelkhalek O, et al. Comparative study of energy management strategies for hybrid proton exchange membrane fuel cell four wheel drive electric vehicle. J Power Sources, 2020, 462: 228167

60 Geng $\mathrm{H}, \mathrm{Wu} \mathrm{H}, \mathrm{Li}$ J, et al. Preparing proton exchange membranes via incorporating silica-based nanoscale ionic materials for the enhanced proton conductivity. Solid State Ion, 2020, 349: 115294

61 Zhang X, Li ZW, Chen XL, et al. Side chain engineering of sulfonated poly(arylene ether)s for proton exchange membranes. Chin J Polym Sci, 2019, 38: 644-652

62 Nor NAM, Jaafar J, Kim JD. Improved properties of sulfonated octaphenyl polyhedral silsequioxane cross-link with highly sulfonated polyphenylsulfone as proton exchange membrane. J Solid State Electrochem, 2020, 24: 1185-1195

$63 \mathrm{Lu} \mathrm{S}, \mathrm{Xu} \mathrm{X}$, Zhang J, et al. A self-anchored phosphotungstic acid hybrid proton exchange membrane achieved via one-step synthesis. Adv Energy Mater, 2014, 4: 1400842

64 Rosli RE, Sulong AB, Daud WRW, et al. A review of high-temperature proton exchange membrane fuel cell (HT-PEMFC) system. Int J Hydrogen Energy, 2017, 42: 9293-9314

65 Gao C, Hu M, Wang L, et al. Synthesis and properties of phosphoric- 
acid-doped polybenzimidazole with hyperbranched cross-linkers decorated with imidazolium groups as high-temperature proton exchange membranes. Polymers, 2020, 12: 515

66 Jang J, Kim DH, Ahn MK, et al. Phosphoric acid doped triazolecontaining cross-linked polymer electrolytes with enhanced stability for high-temperature proton exchange membrane fuel cells. J Membrane Sci, 2020, 595: 117508

67 Sun X, Li Y, Qi F, et al. Degradation studies of single cell and short stack for high temperature proton exchange membrane fuel cells based on $\mathrm{PBI} / \mathrm{H}_{3} \mathrm{PO}_{4}$ membrane. ChemistrySelect, 2019, 4: 12313-12319

68 Mecerreyes D, Grande H, Miguel O, et al. Porous polybenzimidazole membranes doped with phosphoric acid: Highly proton-conducting solid electrolytes. Chem Mater, 2004, 16: 604-607

69 Wang JT, Savinell RF, Wainright J, et al. $\mathrm{A} \mathrm{H}_{2} / \mathrm{O}_{2}$ fuel cell using acid doped polybenzimidazole as polymer electrolyte. Electrochim Acta, 1996, 41: 193-197

70 Barati S, Abdollahi M, Khoshandam B, et al. Highly proton conductive porous membranes based on polybenzimidazole/lignin blends for high temperatures proton exchange membranes: Preparation, characterization and morphology-proton conductivity relationship. Int J Hydrogen Energy, 2018, 43: 19681-19690

71 Devrim Y, Devrim H, Eroglu I. Polybenzimidazole $/ \mathrm{SiO}_{2}$ hybrid membranes for high temperature proton exchange membrane fuel cells. Int J Hydrogen Energy, 2016, 41: 10044-10052

72 Jun $\mathrm{Y}$, Zarrin H, Fowler $\mathrm{M}$, et al. Functionalized titania nanotube composite membranes for high temperature proton exchange membrane fuel cells. Int J Hydrogen Energy, 2011, 36: 6073-6081

73 Zarrin H, Higgins D, Jun Y, et al. Functionalized graphene oxide nanocomposite membrane for low humidity and high temperature proton exchange membrane fuel cells. J Phys Chem C, 2011, 115: 20774-20781

74 Dai Y, Wang J, Tao P, et al. Various hydrophilic carbon dots doped high temperature proton exchange composite membranes based on polyvinylpyrrolidone and polyethersulfone. J Colloid Interface Sci, 2019, 553: 503-511

75 Devrim Y. Fabrication and performance evaluation of hybrid membrane based on a sulfonated polyphenyl sulfone/phosphotungstic acid/ silica for proton exchange membrane fuel cell at low humidity conditions. Electrochim Acta, 2014, 146: 741-751

76 Zhang X, Ai T, Huang Y, et al. Mesoporous silica nanospheres impregnated with 12-phosphotungstic acid as inorganic filler of nafion membrane for proton exchange membrane fuel cells. J Nanosci Nanotechnol, 2019, 19: 98-104

77 van de Ven E, Chairuna A, Merle G, et al. Ionic liquid doped polybenzimidazole membranes for high temperature proton exchange membrane fuel cell applications. J Power Sources, 2013, 222: 202-209

78 Watanabe M, Thomas ML, Zhang S, et al. Application of ionic liquids to energy storage and conversion materials and devices. Chem Rev, 2017, 117: 7190-7239

79 Al-Othman A, Nancarrow P, Tawalbeh M, et al. Novel composite membrane based on zirconium phosphate-ionic liquids for high temperature PEM fuel cells. Int J Hydrogen Energy, 2020, 46: 61006109

80 Lin B, Yuan W, Xu F, et al. Protic ionic liquid/functionalized graphene oxide hybrid membranes for high temperature proton exchange membrane fuel cell applications. Appl Surf Sci, 2018, 455: 295-301

81 Li N, Guiver MD. Ion transport by nanochannels in ion-containing aromatic copolymers. Macromolecules, 2014, 47: 2175-2198

82 Liu F, Wang S, Li J, et al. Polybenzimidazole/ionic-liquid-functional silica composite membranes with improved proton conductivity for high temperature proton exchange membrane fuel cells. J Membrane Sci, 2017, 541: 492-499

83 Sun H, Zuo J, Wang X, et al. Proton transfer reaction in poly(2,5polybenzimidazole) doping with $\mathrm{H}_{3} \mathrm{PO}_{4}$. Int J Hydrogen Energy, 2014, 39: $13808-13815$

84 Daletou MK, Kallitsis JK, Voyiatzis G, et al. The interaction of water vapors with $\mathrm{H}_{3} \mathrm{PO}_{4}$ imbibed electrolyte based on $\mathrm{PBI} /$ polysulfone copolymer blends. J Membrane Sci, 2009, 326: 76-83

$85 \mathrm{Qu} \mathrm{S}, \mathrm{Li} \mathrm{M}$, Zhang $\mathrm{C}$, et al. Improving the proton conductivity of sulfonated poly(ether ether ketone) membranes by incorporating a crystalline nanoassembly of trimesic acid and melamine. Int J Hydrogen Energy, 2019, 45: 29883-29891

86 Hong L, Wang B, Zhao C. Phosphoric acid doped high temperature proton exchange membranes based on comb-shaped polymers with quaternized graft architectures. Appl Surf Sci, 2019, 483: 785-792

87 Yoon YJ, Kim TH, Yu DM, et al. Sulfonated poly(arylene ether sulfone)/disulfonated silsesquioxane hybrid proton conductors for proton exchange membrane fuel cell application. Int J Hydrogen Energy, 2012, 37: 18981-18988

88 Bai H, Ho WSW. New poly(ethylene oxide) soft segment-containing sulfonated polyimide copolymers for high temperature proton-exchange membrane fuel cells. J Membrane Sci, 2008, 313: 75-85

89 Einsla B, Kim Y, Hickner M, et al. Sulfonated naphthalene dianhydride based polyimide copolymers for proton-exchange-membrane fuel cells. II. Membrane properties and fuel cell performance. J Membrane Sci, 2005, 255: 141-148

90 Bai H, Ho WSW. New sulfonated polybenzimidazole (SPBI) copolymer-based proton-exchange membranes for fuel cells. J Taiwan Institute Chem Engineers, 2009, 40: 260-267

91 Adanur S, Zheng $H$. Synthesis and characterization of sulfonated polyimide based membranes for proton exchange membrane fuel cells. J Fuel Cell Sci Tech, 2013, 10: 041001

92 Bano S, Negi YS, Ramya K. Studies on new highly phosphonated poly (ether ether ketone) based promising proton conducting membranes for high temperature fuel cell. Int J Hydrogen Energy, 2019, 44: 28968-28983

93 Li Y, Zhang X, He G, et al. Sulfonated poly(phenylene sulfide) grafted polysulfone proton exchange membrane with improved stability. Int J Hydrogen Energy, 2017, 42: 2360-2369

94 Wang D, Wang S, Tian X, et al. Ethyl phosphoric acid grafted aminomodified polybenzimidazole with improved long-term stability for high-temperature proton exchange membrane applications. Int J Hydrogen Energy, 2020, 45: 3176-3185

95 Li N, Zhang S, Liu J, et al. Synthesis and properties of sulfonated poly [bis(benzimidazobenzisoquinolinones)] as hydrolytically and thermooxidatively stable proton conducting ionomers. Macromolecules, 2008, 41: 4165-4172

96 Bae B, Hoshi T, Miyatake K, et al. Sulfonated block poly(arylene ether sulfone) membranes for fuel cell applications via oligomeric sulfonation. Macromolecules, 2011, 44: 3884-3892

97 Zhang N, Wang B, Zhao C, et al. Dual cross-linked organic-inorganic hybrid polymer electrolyte membranes based on quaternized poly (ether ether ketone) and (3-aminopropyl)triethoxysilane. J Power Sources, 2015, 275: 815-822

98 Chen CF, Juang LJ, Hsu TC, et al. Diacid architecture effect on the synthesis and microstructure of rigid-rod poly(benzobisthiazole)s. Polym Int, 2006, 55: 1450-1455

99 Uno K, Niume K, Iwata Y, et al. Synthesis of polybenzimidazoles with sulfonic acid groups. J Polym Sci Polym Chem Ed, 1977, 15: 13091318

100 Choe EW. Catalysts for the preparation of polybenzimidazoles. J Appl Polym Sci, 1994, 53: 497-506

101 Evers RC, Arnold FE, Helminiak TE. Articulated all-para polymers with 2,6-benzobisoxazole, 2,6-benzobisthiazole, and 2,6-benzobisimidazole units in the backbone. Macromolecules, 1981, 14: 925-930

102 Xiao L, Zhang $\mathrm{H}$, Scanlon E, et al. High-temperature polybenzimidazole fuel cell membranes via a sol-gel process. Chem Mater, 2005, 17: 5328-5333

103 Berber MR, Nakashima N. Bipyridine-based polybenzimidazole membranes with outstanding hydrogen fuel cell performance at high temperature and non-humidifying conditions. J Membrane Sci, 2019 591: 117354

104 Wang G, Lee KH, Lee WH, et al. Durable sulfonated poly(benzothiazole-co-benzimidazole) proton exchange membranes. Macromolecules, 2014, 47: 6355-6364

105 Rozière J, Jones DJ, Marrony M, et al. On the doping of sulfonated polybenzimidazole with strong bases. Solid State Ion, 2001, 145: 61-68 106 Peron J, Ruiz E, Jones DJ, et al. Solution sulfonation of a nove 
polybenzimidazole. J Membrane Sci, 2008, 314: 247-256

107 Qing S, Huang W, Yan D. Synthesis and properties of soluble sulfonated polybenzimidazoles. Reactive Funct Polyms, 2006, 66: 219-227

108 Wang G, Xiao G, Yan D. Synthesis and properties of soluble sulfonated polybenzimidazoles derived from asymmetric dicarboxylic acid monomers with sulfonate group as proton exchange membrane. J Membrane Sci, 2011, 369: 388-396

109 Osaheni JA, Jenekhe SA. Synthesis and processing of heterocyclic polymers as electronic, optoelectronic, and nonlinear optical materials. 1. New conjugated rigid-rod benzobisthiazole polymers. Chem Mater, 1992, 4: 1282-1290

$110 \mathrm{Hu}$ XB, Yu DM. Hyperbranched polybenzobisthiazole with high thermal stability, good organosolubility, and interesting optical performance. Macromol Chem Phys, 2012, 213: 738-746

111 Wang G, Xiao G, Yan D. Soluble sulfonated polybenzothiazoles derived from 3,3'-disulfonate-4,4'-dicarboxylbiphenyl for proton exchange membranes. Int J Hydrogen Energy, 2012, 37: 5170-5179

112 Feng S, Shang Y, Wang S, et al. Novel method for the preparation of ionically crosslinked sulfonated poly(arylene ether sulfone)/polybenzimidazole composite membranes via in situ polymerization. J Membrane Sci, 2010, 346: 105-112

113 Tan N, Chen Y, Xiao G, et al. Synthesis and properties of sulfonated polybenzothiazoles with benzimidazole moieties as proton exchange membranes. J Membrane Sci, 2010, 356: 70-77

114 Tan N, Xiao G, Yan D. Sulfonated polybenzothiazoles: A novel candidate for proton exchange membranes. Chem Mater, 2010, 22: 10221031

115 Hu XD, Jenkins SE, Min BG, et al. Rigid-rod polymers: Synthesis, processing, simulation, structure, and properties. Macromol Mater Eng, 2003, 288: 823-843

116 Wang G, Lee $\mathrm{KH}$, Lee $\mathrm{WH}$, et al. Soluble sulfonated polybenzothiazoles containing naphthalene for use as proton exchange membranes. J Membrane Sci, 2015, 490: 346-353

117 Li N, Cui Z, Zhang S, et al. Sulfonated polyimides bearing benzimidazole groups for proton exchange membranes. Polymer, 2007, 48: 7255-7263

$118 \mathrm{Li}$ W, Guo X, Fang J. Synthesis and properties of sulfonated polyimide-polybenzimidazole copolymers as proton exchange membranes. J Mater Sci, 2014, 49: 2745-2753

119 Zhuang Y, Seong JG, Lee YM. Polyimides containing aliphatic/alicyclic segments in the main chains. Prog Polym Sci, 2019, 92: 35-88

120 Zhang Y, Lee WH, Seong JG, et al. Alicyclic segments upgrade hydrogen separation performance of intrinsically microporous polyimide membranes. J Membrane Sci, 2020, 611: 118363

121 Zhang D, Seong JG, Lee WH, et al. Effects of sulfonate incorporation and structural isomerism on physical and gas transport properties of soluble sulfonated polyimides. Polymer, 2020, 191: 122263

122 Mistri EA, Mohanty AK, Banerjee S. Synthesis and characterization of new fluorinated poly(ether imide) copolymers with controlled degree of sulfonation for proton exchange membranes. J Membrane Sci, 2012, 411-412: 117-129

123 Einsla BR, Hong YT, Kim YS, et al. Sulfonated naphthalene dianhydride based polyimide copolymers for proton-exchange-membrane fuel cells. I. Monomer and copolymer synthesis. J Polym Sci Polym Chem, 2004, 42: 862-874

124 Mandal AK, Bera D, Banerjee S. Sulfonated polyimides containing triphenylphosphine oxide for proton exchange membranes. Mater Chem Phys, 2016, 181: 265-276

125 Guo X, Fang J, Watari T, et al. Novel sulfonated polyimides as polyelectrolytes for fuel cell application. 2. Synthesis and proton conductivity of polyimides from 9,9-bis(4-aminophenyl)fluorene-2,7disulfonic acid. Macromolecules, 2002, 35: 6707-6713

126 Yan J, Liu C, Wang Z, et al. Water resistant sulfonated polyimides based on 4,4'-binaphthyl-1,1',8,8'-tetracarboxylic dianhydride (BNTDA) for proton exchange membranes. Polymer, 2007, 48: 62106214

127 Miyahara T, Miyake J, Matsuno S, et al. A sulfonated polybenzophenone/polyimide copolymer as a novel proton exchange membrane. RSC Adv, 2015, 5: 50082-50086
128 Mandal AK, Ghorai A, Banerjee S. Sulphonated polysilsesquioxanepolyimide composite membranes: Proton exchange membrane properties. Bull Mater Sci, 2020, 43: 192

129 Bauera B, Jonesb DJ, Rozièreb J,et al. Electrochemical characterisation of sulfonated polyetherketone membranes. J New Mater Electrochem Syst, 2000, 3: 93-98

130 Xing P, Robertson GP, Guiver MD, et al. Synthesis and characterization of sulfonated poly(ether ether ketone) for proton exchange membranes. J Membrane Sci, 2004, 229: 95-106

131 Liang J, Ge J, Wu K, et al. Sulfonated polyaryletherketone with pendant benzimidazole groups for proton exchange membranes. J Membrane Sci, 2020, 597: 117626

132 Lei R, Gao L, Jin R, et al. Sulfonated polyimides containing 1,2,4triazole groups for proton exchange membranes. Chin J Polym Sci, 2014, 32: 941-952

133 Haragirimana $\mathrm{A}$, Ingabire $\mathrm{PB}, \mathrm{Zhu} \mathrm{Y}$, et al. Four-polymer blend proton exchange membranes derived from sulfonated poly(aryl ether sulfone)s with various sulfonation degrees for application in fuel cells. J Membrane Sci, 2019, 583: 209-219

134 Meyer G, Gebel G, Gonon L, et al. Degradation of sulfonated polyimide membranes in fuel cell conditions. J Power Sources, 2006, 157 293-301

135 Miyatake K, Yasuda T, Hirai M, et al. Synthesis and properties of a polyimide containing pendant sulfophenoxypropoxy groups. J Polym Sci Polym Chem, 2007, 45: 157-163

$136 \mathrm{Hu} \mathrm{Z}$, Yin Y, Okamoto K, et al. Synthesis and characterization of sulfonated polyimides derived from 2,2'-bis(4-sulfophenyl)-4,4'-oxydianiline as polymer electrolyte membranes for fuel cell applications. J Membrane Sci, 2009, 329: 146-152

137 Cheng $\mathrm{H}, \mathrm{Xu}$ J, Ma L, et al. Preparation and characterization of sulfonated poly(arylene ether ketone) copolymers with pendant sulfoalkyl groups as proton exchange membranes. J Power Sources, 2014 260: 307-316

138 Atanasov V, Oleynikov A, Xia J, et al. Phosphonic acid functionalized poly(pentafluorostyrene) as polyelectrolyte membrane for fuel cell application. J Power Sources, 2017, 343: 364-372

139 Li HQ, Liu XJ, Xu J, et al. Enhanced proton conductivity of sulfonated poly(arylene ether ketone sulfone) for fuel cells by grafting triazole groups onto polymer chains. J Membrane Sci, 2016, 509: 173-181

140 Maruyama J, Inaba M, Ogumi Z. Effect of fluorinated alcohol on the kinetics of cathodic oxygen reduction at gold electrodes. Electrochim Acta, 1999, 45: 415-422

141 Kinumoto T, Inaba M, Nakayama Y, et al. Durability of perfluorinated ionomer membrane against hydrogen peroxide. J Power Sources, 2006, 158: 1222-1228

142 Yin Y, Fang J, Watari T, et al. Synthesis and properties of highly sulfonated proton conducting polyimides from bis(3-sulfopropoxy) benzidine diamines. J Mater Chem, 2004, 14: 1062

143 Yin Y, Yamada O, Suto Y, et al. Synthesis and characterization of proton-conducting copolyimides bearing pendant sulfonic acid groups. J Polym Sci Polym Chem, 2005, 43: 1545-1553

144 Li N, Cui Z, Zhang S, et al. Synthesis and characterization of rigid-rod sulfonated polyimides bearing sulfobenzoyl side groups as proton exchange membranes. J Membrane Sci, 2007, 295: 148-158

145 Shao K, Zhu J, Zhao C, et al. Naphthalene-based poly(arylene ether ketone) copolymers containing sulfobutyl pendant groups for proton exchange membranes. J Polym Sci Polym Chem, 2009, 47: 5772-5783

146 Ponce M, Gomes D, Nunes S. One-pot synthesis of high molecular weight sulfonated poly(oxadiazole-triazole) copolymers for proton conductive membranes. J Membrane Sci, 2008, 319: 14-22

147 Liu YF, Yu QC, Wu YH. Preparation and proton conductivity of composite membranes based on sulfonated poly(phenylene oxide) and benzimidazole. Electrochim Acta, 2007, 52: 8133-8137

148 Bock T, Möhwald H, Mülhaupt R. Arylphosphonic acid-functionalized polyelectrolytes as fuel cell membrane material. Macromol Chem Phys, 2007, 208: 1324-1340

149 Kang NR, Pham TH, Nederstedt H, et al. Durable and highly proton conducting poly(arylene perfluorophenylphosphonic acid) membranes. J Membrane Sci, 2021, 623: 119074 
150 Abouzari-Lotf E, Ghassemi H, Mehdipour-Ataei S, et al. Phosphonated polyimides: Enhancement of proton conductivity at high temperatures and low humidity. J Membrane Sci, 2016, 516: 74-82

151 Adamski M, Skalski TJG, Schibli EM, et al. Molecular branching as a simple approach to improving polymer electrolyte membranes. J Membrane Sci, 2020, 595: 117539

152 Yang P, Xuan S, Long J, et al. Fluorine-containing branched sulfonated polyimide membrane for vanadium redox flow battery applications. ChemElectroChem, 2018, 5: 3695-3707

153 Guo W, Li X, Wang H, et al. Synthesis of branched sulfonated poly(aryl ether ketone) copolymers and their proton exchange membrane properties. J Membrane Sci, 2013, 444: 259-267

154 Suda T, Yamazaki K, Kawakami H. Syntheses of sulfonated star-hyperbranched polyimides and their proton exchange membrane properties. J Power Sources, 2010, 195: 4641-4646

155 Han J, Kim K, Kim J, et al. Cross-linked highly sulfonated poly(arylene ether sulfone) membranes prepared by in-situ casting and thiol-ene click reaction for fuel cell application. J Membrane Sci, 2019, 579: 7078

156 Yang J, Jiang H, Gao L, et al. Fabrication of crosslinked polybenzimidazole membranes by trifunctional crosslinkers for high temperature proton exchange membrane fuel cells. Int J Hydrogen Energy, 2018, 43: 3299-3307

157 Li HQ, Liu XJ, Yang H, et al. Enhanced proton conductivity and relative selectivity of sulfonated poly(arylene ether ketone sulfone) proton exchange membranes by using triazole-grafted 3-glycidyloxypropyltrimethoxysilane. Electrochim Acta, 2018, 291: 49-63

158 Zhang B, Ni J, Xiang X, et al. Synthesis and properties of reprocessable sulfonated polyimides cross-linked via acid stimulation for use as proton exchange membranes. J Power Sources, 2017, 337: 110-117

159 Li X, Ma H, Wang P, et al. Highly conductive and mechanically stable imidazole-rich cross-linked networks for high-temperature proton exchange membrane fuel cells. Chem Mater, 2020, 32: 1182-1191

160 Wang L, Wu Y, Fang M, et al. Synthesis and preparation of branched block polybenzimidazole membranes with high proton conductivity and single-cell performance for use in high temperature proton exchange membrane fuel cells. J Membrane Sci, 2020, 602: 117981

161 Lee S, Seo K, Ghorpade RV, et al. High temperature anhydrous proton exchange membranes based on chemically-functionalized titanium/ polybenzimidazole composites for fuel cells. Mater Lett, 2020, 263: 127167

162 Özdemir Y, Üregen N, Devrim Y. Polybenzimidazole based nanocomposite membranes with enhanced proton conductivity for high temperature PEM fuel cells. Int J Hydrogen Energy, 2017, 42: 26482657

163 Chen H, Wang S, Liu F, et al. Base-acid doped polybenzimidazole with high phosphoric acid retention for HT-PEMFC applications. J Membrane Sci, 2020, 596: 117722

164 Hazarika M, Jana T. Novel proton exchange membrane for fuel cell developed from blends of polybenzimidazole with fluorinated polymer. Eur Polym J, 2013, 49: 1564-1576

165 Hazarika M, Jana T. Proton exchange membrane developed from novel blends of polybenzimidazole and poly(vinyl-1,2,4-triazole). ACS Appl Mater Interfaces, 2012, 4: 5256-5265

166 Koyilapu R, Singha S, Sana B, et al. Proton exchange membrane prepared by blending polybenzimidazole with poly(aminophosphonate ester). Polym Testing, 2020, 85: 106414

167 Bu F, Zhang Y, Hong L, et al. 1,2,4-Triazole functionalized poly(arylene ether ketone) for high temperature proton exchange membrane with enhanced oxidative stability. J Membrane Sci, 2018, 545: 167-175

168 Atanasov V, Lee AS, Park EJ, et al. Synergistically integrated phosphonated poly(pentafluorostyrene) for fuel cells. Nat Mater, 2021, 20: 370-377

169 Yin B, Wu Y, Liu C, et al. An effective strategy for the preparation of a wide-temperature-range proton exchange membrane based on polybenzimidazoles and polyacrylamide hydrogels. J Mater Chem A, 2021, 9: $3605-3615$

170 Wang L, Ni J, Liu D, et al. Effects of branching structures on the properties of phosphoric acid-doped polybenzimidazole as a mem- brane material for high-temperature proton exchange membrane fuel cells. Int J Hydrogen Energy, 2018, 43: 16694-16703

171 Wang L, Liu Z, Liu Y, et al. Crosslinked polybenzimidazole containing branching structure with no sacrifice of effective N-H sites: Towards high-performance high-temperature proton exchange membranes for fuel cells. J Membrane Sci, 2019, 583: 110-117

172 Chen JC, Wu JA, Chen KH. Synthesis and characterization of novel imidazolium-functionalized polyimides for high temperature proton exchange membrane fuel cells. RSC Adv, 2016, 6: 33959-33970

173 Staiti P, Lufrano F, Aricò AS, et al. Sulfonated polybenzimidazole membranes-Preparation and physico-chemical characterization. J Membrane Sci, 2001, 188: 71-78

174 Kerres J, Ullrich A, Meier F, et al. Synthesis and characterization of novel acid-base polymer blends for application in membrane fuel cells. Solid State Ion, 1999, 125: 243-249

175 Schuster M, Rager T, Noda A, et al. About the choice of the protogenic group in PEM separator materials for intermediate temperature, low humidity operation: A critical comparison of sulfonic acid, phosphonic acid and imidazole functionalized model compounds. Fuel Cells, 2005, 5: 355-365

$176 \mathrm{He}$ R. Proton conductivity of phosphoric acid doped polybenzimidazole and its composites with inorganic proton conductors. J Membrane Sci, 2003, 226: 169-184

177 Lin HL, Chen YC, Li CC, et al. Preparation of PBI/PTFE composite membranes from PBI in $N, N^{\prime}$-dimethyl acetamide solutions with various concentrations of LiCl. J Power Sources, 2008, 181: 228-236

178 Yang J, Li Q, Jensen JO, et al. Phosphoric acid doped imidazolium polysulfone membranes for high temperature proton exchange membrane fuel cells. J Power Sources, 2012, 205: 114-121

179 Zhang J, Zhang J, Bai $\mathrm{H}$, et al. A new high temperature polymer electrolyte membrane based on tri-functional group grafted polysulfone for fuel cell application. J Membrane Sci, 2019, 572: 496-503

180 Lee KS, Spendelow JS, Choe YK, et al. An operationally flexible fuel cell based on quaternary ammonium-biphosphate ion pairs. Nat Energy, 2016, 1: 16120

181 Atanasov V, Gudat D, Ruffmann B, et al. Highly phosphonated polypentafluorostyrene: Characterization and blends with polybenzimidazole. Eur Polym J, 2013, 49: 3977-3985

$182 \mathrm{Xu}$ N, Guo X, Fang J, et al. Synthesis of novel polybenzimidazoles with pendant amino groups and the formation of their crosslinked membranes for medium temperature fuel cell applications. J Polym Sci Polym Chem, 2009, 47: 6992-7002

183 Wang S, Zhao C, Ma W, et al. Preparation and properties of epoxycross-linked porous polybenzimidazole for high temperature proton exchange membrane fuel cells. J Membrane Sci, 2012, 411-412: 54-63

184 Han M, Zhang G, Liu Z, et al. Cross-linked polybenzimidazole with enhanced stability for high temperature proton exchange membrane fuel cells. J Mater Chem, 2011, 21: 2187-2193

$185 \mathrm{Li} \mathrm{J}$, Wang S, Liu F, et al. Flame-retardant AEMs based on organicinorganic composite polybenzimidazole membranes with enhanced hydroxide conductivity. J Membrane Sci, 2019, 591: 117306

186 Armand M, Endres F, MacFarlane DR, et al. Ionic-liquid materials for the electrochemical challenges of the future. Nat Mater, 2009, 8: 621629

187 Pandey RP, Shahi VK. Aliphatic-aromatic sulphonated polyimide and acid functionalized polysilsesquioxane composite membranes for fuel cell applications. J Mater Chem A, 2013, 1: 14375

188 Maity S, Singha S, Jana T. Low acid leaching PEM for fuel cell based on polybenzimidazole nanocomposites with protic ionic liquid modified silica. Polymer, 2015, 66: 76-85

189 Linlin M, Mishra AK, Kim NH, et al. Poly(2,5-benzimidazole)-silica nanocomposite membranes for high temperature proton exchange membrane fuel cell. J Membrane Sci, 2012, 411-412: 91-98

190 Pandey RP, Thakur AK, Shahi VK. Sulfonated polyimide/acid-functionalized graphene oxide composite polymer electrolyte membranes with improved proton conductivity and water-retention properties. ACS Appl Mater Interfaces, 2014, 6: 16993-17002

191 Lv Y, Li Z, Song M, et al. Preparation and properties of ZrPA doped CMPSU cross-linked PBI based high temperature and low humidity 
proton exchange membranes. Reactive Funct Polyms, 2019, 137: 5770

192 Wang Y, Sun P, Li Z, et al. Construction of novel proton transport channels by triphosphonic acid proton conductor-doped crosslinked mpbi-based high-temperature and low-humidity proton exchange membranes. ACS Sustain Chem \& Eng, 2021, 9: 2861-2871

$193 \mathrm{Xu}$ C, Wu X, Wang X, et al. Composite membranes of polybenzimidazole and caesium-salts-of-heteropolyacids for intermediate temperature fuel cells. J Mater Chem, 2011, 21: 6014

194 Zhou Z, Li SW, Zhang YL, et al. Promotion of proton conduction in polymer electrolyte membranes by $1 H$-1,2,3-triazole. J Am Chem Soc, 2005, 127: 10824-10825

195 Schechter A, Savinell RF. Imidazole and 1-methyl imidazole in phosphoric acid doped polybenzimidazole, electrolyte for fuel cells. Solid State Ionics, 2002, 147: 181-187

196 Wang J, Yue Z, Economy J. Preparation of proton-conducting composite membranes from sulfonated poly(ether ether ketone) and polyacrylonitrile. J Membrane Sci, 2007, 291: 210-219

197 Lu S, Xiu R, Xu X, et al. Polytetrafluoroethylene (PTFE) reinforced poly(ethersulphone)-poly(vinyl pyrrolidone) composite membrane for high temperature proton exchange membrane fuel cells. J Membrane Sci, 2014, 464: 1-7

198 Ren X, Li H, Liu K, et al. Preparation and investigation of reinforced PVP blend membranes for high temperature polymer electrolyte membranes. Fibers Polym, 2019, 19: 2449-2457

199 Imran MA, He G, Wu X, et al. Fabrication and characterization of sulfonated polybenzimidazole/sulfonated imidized graphene oxide hybrid membranes for high temperature proton exchange membrane fuel cells. J Appl Polym Sci, 2019, 136: 47892

200 Hasiotis C, Qingfeng L, Deimede V, et al. Development and characterization of acid-doped polybenzimidazole/sulfonated polysulfone blend polymer electrolytes for fuel cells. J Electrochem Soc, 2001, 148: A513

201 Tang Q, Yuan S, Cai H. High-temperature proton exchange membranes from microporous polyacrylamide caged phosphoric acid. J Mater Chem A, 2013, 1: 630-636

202 Geng K, Tang H, Ju Q, et al. Symmetric sponge-like porous polybenzimidazole membrane for high temperature proton exchange membrane fuel cells. J Membrane Sci, 2021, 620: 118981

203 Singha S, Jana T. Effect of composition on the properties of PEM based on polybenzimidazole and poly(vinylidene fluoride) blends. Polymer, 2014, 55: 594-601

204 Kuo SW, Tsai HT. Complementary multiple hydrogen-bonding interactions increase the glass transition temperatures to PMMA copolymer mixtures. Macromolecules, 2009, 42: 4701-4711

205 Lu S, Zhuang L, Lu J. Homogeneous blend membrane made from poly(ether sulphone) and poly(vinylpyrrolidone) and its application to water electrolysis. J Membrane Sci, 2007, 300: 205-210

206 Tan Y, Zhang K, Liao H, et al. Sulfonated poly(arylene thioether phosphine oxide)s (SPTPO) and SPTPO/sulfonated polybenzothiazole blends as proton exchange membranes. RSC Adv, 2016, 6: $21367-$ 21375

207 Yuan Q, Liu P, Baker GL. Sulfonated polyimide and PVDF based blend proton exchange membranes for fuel cell applications. J Mater Chem A, 2015, 3: 3847-3853

Acknowledgements This work was supported by the National Key Research and Development Program of China (2019YFC1906602), the National Natural Science Foundation of China (U1904171), the Foundation for "Talent Program", the Open Fund of the State Key Laboratory of Biochemical Engineering, Institute of Process Engineering (IPE), Chinese Academy of Sciences (CAS), the Project Fund of Jiangsu Bingcheng Hydrogen Energy Technology Co., Ltd., and the Young Backbone Teachers Training Program Foundation of Henan University of Technology.

Author contributions Dai J, Wang G and Zhuang Y wrote the manuscript. Zhang Y participated in the discussion.
Conflict of interest The authors declare that they have no conflict of interest.

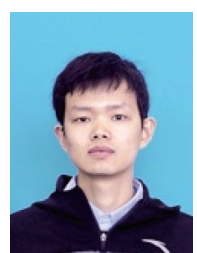

Junming Dai is a PhD student at the Institute of Process Engineering (IPE), Chinese Academy of Sciences (CAS) in China. He received his master's degree from Harbin Institute of Technology, Weihai. His research mainly focuses on the rational design and synthesis of high-conductivity polybenzimidazole and polyimide materials for membrane applications.

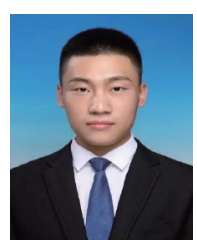

Yu Zhang is a PhD student at the IPE, CAS in China. He received his BS degree from China University of Petroleum, Beijing. His research interests include the synthesis and modification of microporous polyimide for membrane applications.

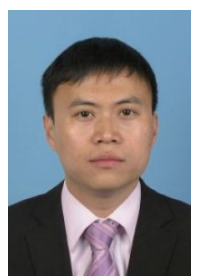

Gang Wang is an associate professor at Henan University of Technology (China). He obtained his $\mathrm{PhD}$ degree (2012) from Shanghai Jiao Tong University (China). He worked as a postdoctoral associate at Hanyang University (Korea) from 2013 to 2014. His research field is the synthesis and properties of PEM, especially in sulfonated polybenzimidazoles and polybenzothiazoles as PEMs.

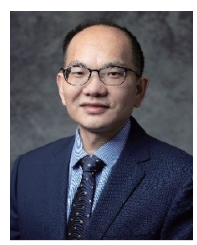

Yongbing Zhuang is a Professor at the IPE, CAS. He received his $\mathrm{PhD}$ degree in polymer science and engineering from Sichuan University (China) in 2011. He worked as a postdoctoral associate at Hanyang University (Korea) and Laval University (Canada) between 2013 and 2015. Before joining the IPE, CAS, he worked as a research fellow of the Japan Society for the Promotion of Science (JSPS) at Tokyo Institute of Technology (Japan) in 2016. His recent research interests include the design and development of high-resistance polymer film/membrane materials for various functional applications (e.g., gas separation membranes and PEMs)

\section{高温燃料电池用聚合物质子交换膜的结构构筑}

代俊明 1,3 , 张宇 ${ }^{1,3}$, 王刚 ${ }^{2 *}$, 庄永兵 ${ }^{1,3^{*}}$

摘要 高温质子交换膜 (HT-PEM) 燃料电池与低温质子交换膜燃料电 池相比具有许多优点. 高导电性、低湿度操作条件、优异的机械性能 和低成本是高温质子交换膜的基本要求. 为了满足高温条件下的应用 要求, 可在聚合物主链引入苯并咪唑、苯并噻唑、酰亚胺和醚醚酮等 各种分子结构单元. 基于主链骨架的磺化聚合物是用于改善质子传导 能力和其他性能最常见的结构设计策略. 磷酸掺杂的聚苯并咪唑(PBIs) 是目前用于HT-PEM的最成功的聚合物膜材料. 为进一步提高HT-PME 的导电性、热稳定性和机械性能, 可通过多种有效的分子结构设计策 略进行改性, 具体方案包括侧链工程(如在侧链上引入 $\mathrm{SO}_{3}{ }^{-}$、接枝、支 化和交联等)和复合、共混改性. 本文总结了HT-PEM用聚合物膜材料 分子链结构设计的研究进展, 系统地讨论了含有特定分子结构链骨架 的聚合物合成方法及性能，分析和总结了高温质子交换膜的改性方法, 展望了其应用前景和未来面临的挑战. 